\title{
Iron Transformation Pathways and Redox Micro-Environments in Seafloor Sulfide-Mineral Deposits: Spatially Resolved Fe XAS and $\delta^{57 / 54} \mathrm{Fe}$ Observations
}

\author{
Brandy M. Toner ${ }^{1 *}$, Olivier J. Rouxel ${ }^{2}$, Cara M. Santelli ${ }^{3}$, Wolfgang Bach ${ }^{4}$ and \\ Katrina J. Edwards ${ }^{5+}$ \\ ${ }^{1}$ Département des Ressources Physiques et Écosystèmes de Fond de Mer, Water, and Climate, University of \\ Minnesota-Twin Cities, St. Paul, MN, USA, ${ }^{2}$ Department of Deep-sea Physical Resources and Ecosystems, Centre de Brest, \\ Institut Français de Recherche pour l'Exploitation de la Mer, Plouzané, France, ${ }^{3}$ Department of Earth Sciences, University of \\ Minnesota-Twin Cities, Minneapolis, MN, USA, ${ }^{4}$ Department of Geosciences and MARUM, University of Bremen, Bremen, \\ Germany, ${ }^{5}$ Department of Biological Sciences, University of Southern California, Los Angeles, CA, USA
}

\section{OPEN ACCESS}

Edited by:

Mark Alexander Lever, ETH Zürich, Switzerland

Reviewed by:

Aude Picard,

Harvard University, USA

Julie L. Meyer,

University of Florida, USA

*Correspondence: Brandy M. Toner toner@umn.edu

${ }^{\dagger}$ Deceased.

Specialty section This article was submitted to Extreme Microbiology,

a section of the journal Frontiers in Microbiology

Received: 06 January 2016 Accepted: 18 April 2016 Published: 10 May 2016

Citation:

Toner BM, Rouxel OJ, Santelli CM, Bach W and Edwards KJ (2016) Iron Transformation Pathways and Redox Micro-Environments in Seafloor Sulfide-Mineral Deposits: Spatially Resolved Fe XAS and $\delta^{57 / 54} \mathrm{Fe}$ Observations Front. Microbiol. 7:648. doi: 10.3389/fmicb.2016.00648
Hydrothermal sulfide chimneys located along the global system of oceanic spreading centers are habitats for microbial life during active venting. Hydrothermally extinct, or inactive, sulfide deposits also host microbial communities at globally distributed sites. The main goal of this study is to describe Fe transformation pathways, through precipitation and oxidation-reduction (redox) reactions, and examine transformation products for signatures of biological activity using Fe mineralogy and stable isotope approaches. The study includes active and inactive sulfides from the East Pacific Rise $9^{\circ} 50^{\prime} \mathrm{N}$ vent field. First, the mineralogy of Fe(III)-bearing precipitates is investigated using microprobe X-ray absorption spectroscopy ( $\mu$ XAS) and X-ray diffraction ( $\mu$ XRD). Second, laser-ablation $(\mathrm{LA})$ and micro-drilling (MD) are used to obtain spatially-resolved Fe stable isotope analysis by multicollector-inductively coupled plasma-mass spectrometry (MC-ICP-MS). Eight Fe-bearing minerals representing three mineralogical classes are present in the samples: oxyhydroxides, secondary phyllosilicates, and sulfides. For Fe oxyhydroxides within chimney walls and layers of Si-rich material, enrichments in both heavy and light $\mathrm{Fe}$ isotopes relative to pyrite are observed, yielding a range of $\delta^{57} \mathrm{Fe}$ values up to $6 \%$. Overall, several pathways for Fe transformation are observed. Pathway 1 is characterized by precipitation of primary sulfide minerals from Fe(Il)aq-rich fluids in zones of mixing between vent fluids and seawater. Pathway 2 is also consistent with zones of mixing but involves precipitation of sulfide minerals from Fe(II)aq generated by Fe(III) reduction. Pathway 3 is direct oxidation of $\mathrm{Fe}(\mathrm{II})$ aq from hydrothermal fluids to form $\mathrm{Fe}$ (III) precipitates. Finally, Pathway 4 involves oxidative alteration of pre-existing sulfide minerals to form Fe(III). The Fe mineralogy and isotope data do not support or refute a unique biological role in sulfide alteration. The findings reveal a dynamic range of Fe transformation pathways consistent with a continuum of micro-environments having variable redox conditions. These micro-environments likely support redox cycling of $\mathrm{Fe}$ and $S$ and are consistent with culture-dependent and -independent assessments of microbial physiology and genetic diversity of hydrothermal sulfide deposits.

Keywords: hydrothermal, East Pacific Rise, X-ray absorption spectroscopy, stable isotopes, micro-environment, mineral alteration, iron, biosignature 


\section{INTRODUCTION}

Seafloor hydrothermal activity at oceanic spreading centers is one of the fundamental processes controlling the exchange of heat and chemical species between seawater and ocean rocks (Edmond et al., 1979; Stein and Stein, 1994; Elderfield and Schultz, 1996; Wheat et al., 2004). The altered rock and mineral deposits created by hydrothermal circulation are known to harbor microbial communities with ecological and functional characteristics corresponding to the chemistry of the host substrate (Santelli et al., 2008; Orcutt et al., 2011; Sylvan et al., 2012; Lever et al., 2013; Toner et al., 2013). In addition, it has been demonstrated that microorganisms interact with their rock/mineral environment by promoting mineral dissolution and precipitation (Holden and Adams, 2003; Houghton, 2007; Pagé et al., 2008; Templeton et al., 2009; Houghton and Seyfried, 2010). Investigations of the physiological and phylogenetic diversity of rock-hosted prokaryotes using both culture-based and molecular approaches show their important ecological roles in biogeochemical cycles of carbon $(\mathrm{C})$, sulfur $(\mathrm{S})$, nitrogen $(\mathrm{N})$, and iron (Fe) (Reysenbach and Cady, 2001; Slobodkin et al., 2001; Edwards et al., 2003a; Byrne et al., 2009; Yamamoto and Takai, 2011).

The development of microbial habitats within hydrothermal chimney deposits is a combination of physical (temperature, porosity), chemical (dissolved and mineral), and biological factors (biofilms, mineral alteration). It is well-established that steep temperature and geochemical gradients form within the walls of actively venting chimneys (Tivey, 1995). Corresponding changes in microbial communities along physical and chemical gradients have been demonstrated at various levels of spatial resolution (Karl, 1995; Schrenk et al., 2003; Nakagawa et al., 2005; Pagé et al., 2008; Takai et al., 2008; Callac et al., 2015). The development of micro-environments within chimneys could explain the diverse genetic potential and wide range of metabolisms observed in organisms cultured from sulfide deposits. Analytical tools able to measure chemical, mineralogical, and isotopic information on the micron spatial scale are available, and the geoscience community has begun to apply them in concert (Marcus et al., 2015). Through the combination of these analytical approaches, one can now define the properties of micro-environments and gain the information needed to interpret micro-habitats or micro-niches within rock and mineral substrates.

In mid-ocean ridge (MOR) hydrothermal systems, $\mathrm{Fe}$ is a fundamental element (Emerson, 2016). Iron deserves special attention when considering the biogeochemistry of mid-ocean ridges because it: (1) is abundant in most vent fluids; (2) has dynamic solubility properties and precipitates with $\mathrm{S}$ to form part of the physical structure of sulfide deposits; (3) has dynamic oxidation-reduction (redox) properties and the ability to set and record redox conditions within fluid flow paths; and (4) is a potential substrate for microbial energy (Fe reduction) and respiration (Fe oxidation). In mid-ocean ridge systems, such as the East Pacific Rise at $9-10^{\circ} \mathrm{N}$ or Juan de Fuca Ridge Main Endeavor Field, the breadth of possible biogeochemical roles for $\mathrm{Fe}$ is fully populated. Hydrothermal sulfides are observed as active and inactive chimneys, massive sulfide deposits, and particles in hydrothermal plumes settling from the water column (Feely et al., 1992, 1994; Hannington et al., 1995; Tivey, 2007; Rouxel et al., 2008a; Toner et al., 2009a; Fouquet et al., 2010; Yucel et al., 2011; Breier et al., 2012). Iron (oxyhydr)oxide crusts form through the alteration of Fe-rich basalts and sulfides, and as microbial mats associated with diffuse venting (Alt, 1988; Mills and Elderfield, 1995; Wheat et al., 2000; Boyd and Scott, 2001; Emerson and Moyer, 2002; Edwards et al., 2011). The oxidizing conditions at the seafloor create a driving force for conversion of hydrothermally derived Fe(II)aq, as well as ferrous $\mathrm{Fe}$ in basalt and sulfide minerals, to Fe(III)-bearing minerals through chemical and biological means (Feely et al., 1994; Field and Sherrell, 2000; Edwards et al., 2003b; Toner et al., 2009b). In addition to the mineral forms of $\mathrm{Fe}$, complexes with particulate and dissolved organic matter occur (Bennett et al., 2008; Toner et al., 2009a; Breier et al., 2012; Hawkes et al., 2013) and microorganisms take up hydrothermal Fe in plumes by a variety of mechanisms (Li et al., 2014).

Despite our understanding of the potential (bio)geochemical pathways for $\mathrm{Fe}$ transformation in hydrothermal systems, the actual $\mathrm{Fe}$ pools and most important mechanisms of transformation are difficult to measure and are an area of active research (Saito et al., 2013; Fitzsimmons et al., 2014; Resing et al., 2015). The strategic application of analytical tools over a range of spatial scales, from dissolved Fe species over a $1000 \mathrm{~km}$ to particulate $\mathrm{Fe}$ species within submicron aggregates, presents a way forward. In this contribution, we investigate the $\mu \mathrm{m}$ - to mm-scale chemistry of active and extinct hydrothermal sulfide deposits using micro-probe X-ray diffraction ( $\mu \mathrm{XRD})$, microprobe Fe 1s X-ray absorption spectroscopy ( $\mu$ XAS), and spatially resolved Fe stable isotopes (laser ablation and micro-drilling). The main goal of this study is to describe the Fe transformation pathways in natural sulfide mineral deposits at the seafloor, and examine the products of alteration for indications or markers of biological activity. The research is an extension of incubation studies that subjected polished hydrothermal sulfide samples to seafloor conditions over a known period of time (Edwards et al., 2003b; Toner et al., 2009b) and Fe isotope studies of seafloor hydrothermal vents (Rouxel et al., 2004, 2008a). For our study of natural sulfide mineral alteration, we chose the East Pacific Rise (EPR) $9-10^{\circ} \mathrm{N}$ area because hydrothermally inactive sulfide deposits from this location are known to host microbial communities with the genetic potential to alter Feand S-bearing minerals through redox reactions (Sylvan et al., 2012; Toner et al., 2013). Our investigation reveals a suite of complex Fe transformation pathways, each of which can be partial or complete. We find that metastable Fe oxyhydroxide minerals persist in the samples despite strong evidence for dynamic Fe transformations, and that Fe isotopic fractionation creates very light isotopic signatures $\left(\delta^{57} \mathrm{Fe}\right.$ values as low as $-7 \%$ ) for Fe oxyhydroxides in some samples but isotopically heavy in others. The most important outcome of this work is a record of micro-environments within active and inactive sulfide deposits. These micro-environments are consistent with the diverse genetic potential, and correspondingly wide range of potential metabolisms, observed in organisms cultured from 
sulfide deposits. Micro-environments favorable to microbial Fe and $\mathrm{S}$ oxidation and reduction are supported by mineral and isotopic signatures. However, we did not identify any uniquely biological signatures and attribute this outcome to the complex interplay between biotic and abiotic reactions.

\section{METHODS AND MATERIALS}

\section{Sample Collection and Processing}

Hydrothermally active and inactive sulfide samples were collected from chimneys and massive sulfide deposits during an $R / V$ Atlantis-DSV Alvin cruise to the East Pacific Rise (EPR) Clipperton and Siquieros Fracture Zones $9^{\circ} 28^{\prime} \mathrm{N}-9^{\circ} 51^{\prime} \mathrm{N}$ in 2004. On Alvin dives 4053, 4057, and 4059, samples rich in $\mathrm{Zn}$ and $\mathrm{Fe}$ were collected from: (1) K Vent; (2) north of Bio 9 Vent; (3) south east of Bio 9 Vent; and (4) an extinct, off-axis chimney (Figures S1, S2). Seafloor samples were collected in individual bio-boxes attached to Alvin's basket to avoid cross contamination and minimize exposure to surface sea water. Once on board, the samples were stored in the bio-boxes in the $4^{\circ} \mathrm{C}$ cooler until they were processed in the lab. The samples were placed on sterile Al-foil and sterile tools were used to split subsamples for microbiology and mineralogy studies. Samples for geochemical analysis were allowed to air-dry shipboard and were stored under ambient conditions until embedding and sectioning. Although residual reduced vent fluids in the active chimneys could oxidize during sample transport and handling, the amount of $\mathrm{Fe}$ in residual pore water relative to $\mathrm{Fe}$ in the overall sample is small. Therefore, transformations of Fe during sample transport and handling are not expected to affect the overall analysis of the samples. The sulfide mineral composition and associated microbial communities for the sample set has been described previously (Rouxel et al., 2008a; Sylvan et al., 2012; Toner et al., 2013). The samples for this study are listed in Table S1.

$\mathrm{K}$ Vent is an active sulfide mound hosting spires and relic chimney debris (i.e., rubble). K Vent samples have the unique identifier $E P R-4053-M$ and the three samples were: EPR-4053M3, rubble; EPR-4053-M1-A1, and EPR-4053-M1-A2, both are active spire samples (Figure S3). K Vent sulfides have central conduits of sphalerite $(\mathrm{ZnS})$, marcasite $\left(\mathrm{FeS}_{2}\right)$, and silica-rich materials while the external walls are composed of sphalerite, pyrite $\left(\mathrm{FeS}_{2}\right)$, and silica (Rouxel et al., 2008a). The inactive massive sulfide samples (EPR-4057-M2 and EPR-4059-M3) are from two different locations in the vicinity of Bio 9 Vent. EPR4057-M2 has a relic central conduit of marcasite with finely disseminated sphalerite and pyrite throughout, and an external wall of marcasite and Fe oxyhydroxides. EPR-4059-M3 also has a marcasite conduit with sphalerite-pyrite core and sphaleritepyrite lined fossil tube worms. The extinct, off-axis chimney EPR-4059-M4 lacks a central conduit and has cm-thick sphalerite layers that transition to sphalerite-pyrite and an external wall covered with $\mathrm{Fe}$ oxides and silica.

Air-dry rock specimens were embedded in Epo-tek 301 two-part epoxy (Epoxy Technology). Cross-sections were cut with a wafering saw and adhered to standard glass microscope slides for polishing: producing coarsely polished thick sections (Figure S4). One sample, EPR-4059-M3, has a micro-probe quality polished section ( $30 \mu \mathrm{m}$; Spectrum Petrographics, Inc.). The polished sections were used for synchrotron radiation $\mathrm{X}$ ray microprobe measurements while thick sections were used for laser-ablation and micro-drilling for isotope analysis.

\section{Scanning Electron Microscopy (SEM)}

Subsamples of several EPR sulfides were fixed in $4 \%$ paraformaldehyde at room temperature for $4 \mathrm{~h}$, rinsed with a 1:1 phosphate buffer solution (PBS), and stored in PBS-ethanol at $-20^{\circ} \mathrm{C}$ shipboard. Sample EPR-4059-M4 was subjected to critical point drying and platinum sputter coating prior to SEM imaging at the University of Minnesota, Characterization Facility with a field emission gun scanning electron microscope (JEOL 6500).

\section{Synchrotron Microprobe X-Ray Absorption Spectroscopy (XAS) Analysis}

Iron speciation was measured by $\mathrm{Fe}$ 1s XAS in fluorescence mode at the hard X-ray microprobe beamline 10.3.2, Advanced Light Source (ALS), Lawrence Berkeley National Laboratory, Berkeley, CA (Manceau et al., 2002; Marcus et al., 2004). The monochromator was calibrated by setting the inflection point of an Fe 1s XAS spectrum, collected from an Fe foil, to $7110.75 \mathrm{eV}$ (Kraft et al., 1996). The distribution of elements in polished sections was determined by micro-focused X-ray fluorescence ( $\mu \mathrm{XRF}$ ) mapping using a seven-element Ge solidstate fluorescence detector (Canberra). X-ray fluorescence maps at multiple incident energies were collected to determine the distribution of elements, including $\mathrm{Si}, \mathrm{S}, \mathrm{Ca}, \mathrm{Mn}, \mathrm{Fe}, \mathrm{Co}, \mathrm{Cu}, \mathrm{Ni}$, $\mathrm{Zn}$, and As. These XRF maps were then dead-time corrected, registered, and combined into a single composite map with custom beam-line software (Marcus et al., 2004). Composite XRF maps were used to locate sample locations for point Fe XAS data collection. XRF map measurements used $3 \times 3 \mu \mathrm{m}^{2}$ beam spot on the sample.

Iron 1s spectra in the X-ray absorption near edge structure (XANES) energy range were used to survey the oxidation state and mineral class of the Fe-bearing phases. Iron 1s spectra in the extended X-ray absorption fine structure (EXAFS) energy range were conducted in selected locations to better describe the type of Fe oxyhydroxide phases present. XANES and EXAFS measurements used $10 \times 3 \mu \mathrm{m}^{2}$ beam spot on the sample. Iron EXAFS data collection to a reciprocal space (k-space, $\AA^{-1}$ ) value of 14.4 was attempted in all cases to provide adequate resolution for second shell $\mathrm{Fe}-\mathrm{Fe}$ interatomic distances (Combes et al., 1989). However, the final usable EXAFS data range (based on signal to noise quality) extended to 11.75 to $12.6 \AA^{-1}$ and shell-by-shell fitting was not performed. All Fe 1s spectra were dead-time corrected, energy calibrated, averaged, pre-edge subtracted, and post-edge normalized. Iron EXAFS scans were spline subtracted and converted to reciprocal space (Marcus et al., 2004; Webb, 2005). Iron XANES spectra were corrected for over-absorption induced distortion:

$$
\mu_{\text {corrected }}=\mu_{\text {exp }} /\left(1+a\left(1-\mu_{\exp }\right)\right)
$$


where $a$ was adjusted to obtain agreement between the corrected spectrum and high quality reference standards. Iron EXAFS data collection targeted sample locations with low over-absorption induced distortion; therefore, EXAFS spectra were not corrected for the phenomenon.

Iron XANES (43 spectra) and EXAFS (8 spectra) data were subjected to principal component (PCA) and target transformation (TTA) analysis using SixPack and BL10.3.2 software using methods described previously (Manceau et al., 2002; Webb, 2005; Toner et al., 2006; Breier et al., 2012). Subsequently, linear combination fitting (LCF) of experimental spectra was performed using a library of standards (Hansel et al., 2003; Marcus et al., 2008; Toner et al., 2009b) and custom beamline software (Marcus et al., 2004). A summary of the reference materials is presented in Table S2. The biogenic Fe oxyhydroxide reference spectrum was collected from an $\mathrm{Fe}$ encrusted biofilm (composed of twisted-stalk microbial particles) formed on porous chimney sulfide chips during a 2 month incubation near the Juan de Fuca Ridge (Edwards et al., 2003b). Iron EXAFS was used to describe the Fe-precipitates as polymerized $\mathrm{Fe}$ (III) with short-range structure characterized by edge-sharing features and little three-dimensional ordering (Toner et al., 2009b). The best LCF was chosen based on the normalized sum square parameter (NSS):

$$
N S S=100 \times\left[\sum\left(\mu_{\exp }-\mu_{f i t}\right)^{2} / \sum\left(\mu_{\exp }\right)^{2}\right]
$$

where the addition of a spectral component to the fit required a $10 \%$ or greater improvement in the NSS value. The Fe XAS reference materials deemed most appropriate for this dataset via PCA-TTA are listed in Table S2. The error on the percentages of species present is estimated to be $\pm 10 \%$.

\section{Synchrotron Radiation X-Ray Diffraction}

$\mathrm{X}$-ray diffraction (XRD) patterns were collected for sample EPR4053-M2 from a polished thick section at the ALS, Lawrence Berkeley National Laboratory, Berkeley, CA, USA, on beamline 7.3.3 (Tamura et al., 2002). While Fe XANES and EXAFS are effective at distinguishing among mineralogical classes, in certain cases, they do not provide strong distinction among minerals within the same class (O'Day et al., 2004; Prietzel et al., 2007). For this sample, XRD was used to verify Fe XANES and EXAFS observations of the mineral goethite $(\alpha-\mathrm{FeOOH})$. The area of interest for XRD data collection was located using XRF mapping. The XRD patterns were collected with a CCD camera in reflection mode with a $6.3 \mathrm{keV}$ incident energy and $15 \times 8.5 \mu \mathrm{m}^{2}$ spot size at the sample. The diffraction patterns were processed with the software XMAS for comparison to standards (Tamura et al., 2003).

\section{Multi-Collector Inductively Coupled Plasma Mass Spectrometry (MC-ICP-MS)}

Fine scale variations of $\mathrm{Fe}$ and $\mathrm{S}$ isotope compositions of $\mathrm{Fe}$ oxyhydroxides and pyrite across chimney walls were primarily analyzed using laser ablation technique coupled to multicollector inductively coupled plasma mass spectrometry (MC-ICP-MS). Micro-drilling was also used to allow matrix-free Fe-isotope analysis of mixed Fe-Si oxide and sulfide minerals after complete chemical purification following previously developed methods (Rouxel et al., 2005, 2008a).

For coupled $\mathrm{Fe}$ - and S-isotope analysis of pyrite, we adapted a technique previously used by (Craddock et al., 2008) for the determination of ${ }^{34} S /{ }^{32} S$ isotope ratios in Sbearing minerals. We used a Nd:YAG deep UV (213 nm) laser ablation system (NewWave ${ }^{\mathrm{TM}}$ UP213) coupled to MC-ICP-MS (Neptune, Thermo Scientific) operating at the Woods Hole Oceanographic Institution. The use of high resolution sectorfield mass spectrometry removes major isobaric interferences on S-isotopes from $\mathrm{O}^{2+}$, as already described in numerous studies (Mason et al., 2006; Craddock et al., 2008; Paris et al., 2013). A similar high-resolution approach was used for Fe-isotope analysis (Graham et al., 2004; Horn et al., 2006; Nishizawa et al., 2010). For the simultaneous analysis of both Fe- and S-isotope values in pyrite, our method involved data acquisition in two sequences (i.e., peak jumping mode) allowing the simultaneous determination of ${ }^{32} \mathrm{~S},{ }^{33} \mathrm{~S},{ }^{34} \mathrm{~S}$ (sequence 1), and ${ }^{52} \mathrm{Cr},{ }^{54} \mathrm{Fe},{ }^{57} \mathrm{Fe}$ (sequence 2). This approach allows determining high-precision ${ }^{34} \mathrm{~S} /{ }^{32} \mathrm{~S}$ and ${ }^{57} \mathrm{Fe} /{ }^{54} \mathrm{Fe}$ and on-line correction of potential ${ }^{54} \mathrm{Cr}$ interference on ${ }^{54} \mathrm{Fe}$ using ${ }^{52} \mathrm{Cr}$.

The laser setup was similar to a published method (Craddock et al., 2008): spot diameter of $60 \mu \mathrm{m}, 10 \mathrm{~Hz}$ pulse rate, laser intensity $50-70 \%$, energy density $9-10 \mathrm{j} / \mathrm{cm}^{2}$. Note that under these conditions, ${ }^{56} \mathrm{Fe}$ signal intensity was found to be $>50 \mathrm{~V}$ in some cases (i.e., maximum signal measurable on the Neptune Faraday cups), precluding the measurement of $\delta^{56} \mathrm{Fe}$ values. For the determination of only Fe-isotope ratios in pyrite and $\mathrm{Fe}$ oxyhydroxide, we also used a peak jumping mode as follows: ${ }^{54} \mathrm{Fe},{ }^{56} \mathrm{Fe},{ }^{57} \mathrm{Fe},{ }^{58} \mathrm{Fe}+{ }^{58} \mathrm{Ni},{ }^{60} \mathrm{Ni},{ }^{61} \mathrm{Ni},{ }^{62} \mathrm{Ni}$ (sequence 1 ), ${ }^{52} \mathrm{Cr}$ (sequence 2), ${ }^{32} \mathrm{~S}$ (sequence 3 ), ${ }^{28} \mathrm{Si}$ (sequence 4 ). Using this approach, all $\mathrm{Fe}$ isotopes could be determined together with $\mathrm{Ni}$ isotopes $\left({ }^{62} \mathrm{Ni} /{ }^{60} \mathrm{Ni}\right)$ that are used for mass bias correction. ${ }^{52} \mathrm{Cr}$ was also measured to allow minor isobaric correction on ${ }^{54} \mathrm{Fe}$. The measurements of ${ }^{32} \mathrm{~S}$ and ${ }^{28} \mathrm{Si}$ also allowed us to check for the potential presence of silica (e.g., amorphous silica) and pyrite during analysis of $\mathrm{Fe}$-oxyhydroxides. Operating parameters for laser analysis of Fe isotopes were optimized in order to provide the most stable signal intensities during ablation. The laser was operated under the same setup as for coupled S-Fe isotope measurements but with a smaller spot size of $25 \mu \mathrm{m}$ to obtain a maximum signal on ${ }^{56} \mathrm{Fe}$ below $40 \mathrm{~V}$.

As discussed in Craddock et al., 2008, a line scan ("raster") protocol was used in preference to a single crater mode in order to obtain a higher and more uniform rate of material removal with respect to time. The raster mode utilizes a movable sample stage under a fixed laser beam to generate the desired raster pattern. The size of the trench formed during ablation was about $200 \mu \mathrm{m}$ in cross-sectional area. A scan speed of $5 \mu \mathrm{m} \mathrm{s}^{-1}$ was used during ablation. Total acquisition time was about $4 \mathrm{~min}$ and results in ablation of about $15 \mu \mathrm{g}$ of sample. The signal intensity was monitored to ensure that transport of sample into the ICPMS does not significantly diminish as material is ablated during analysis.

The laser was connected directly to a PFA scott-type spray chamber (Savillex) via $3 \mathrm{~mm}$ internal diameter Tygon tubing and 
used helium (He) as the carrier gas from the laser to the ICP. The setup was such that laser ablation and solution aspiration could be operated simultaneously to enable laser ablated particles to be efficiently mixed with an ultra-pure $0.28 \mathrm{M} \mathrm{HNO}_{3}$ blank solution prior to injection into the ICP torch. Thus, particles were effectively analyzed as a "wet plasma" ensuring that ablated aerosols were closely matrix-matched to solution standards. Since solution and in situ laser analysis was performed interchangeably with identical instrumental setup, the correction of instrumental mass bias used a combination of the "sample-standard bracketing technique" as well as internal normalization technique (i.e., $\mathrm{Ni}$ isotopes). Here, we used Ni isotope standard NIST 986 of known isotope composition. For coupled Fe- and S-isotope analysis $34 \mathrm{~S}$ ) of pyrite, the data were calibrated against $\delta^{57} \mathrm{Fe}$ and $\delta$ (i.e., aqueous standards prepared in appropriate matrix composition (molar S/Fe ratios at 2) and two internal pyrite standards GAV-18 and FL-19-09. The concentrations of Fe and S (i.e., sulfate form) solution prepared from internal standards (Spex Certiprep) in $0.28 \mathrm{M} \mathrm{HNO}_{3}$ were adjusted to obtain similar signal intensity of the ablated sample and bracketing standard solution, typically with less than $20 \%$ difference g/g of Fe and S). When only Feisotope $\mu$ (corresponding to about $10{ }^{57} \mathrm{Fe}$ ), bracketing standard solutions $\delta^{56} \mathrm{Fe}$ and $\delta$-values were measured (g/g). During each laser $\mu \mathrm{g} / \mathrm{g}$ to $5 \mu$ were prepared at a concentration of two analysis run, a Ni standard solution was introduced continuously in the spray chamber and mixed with sample aerosols to allow internal mass bias corrections as described elsewhere (Poitrasson and Freydier, 2005; Rouxel et al., 2005). An example laser isotopic run is presented in Figure S5.

We have examined and determined rigorous corrections for analytical difficulties such as instrumental mass bias, unresolved isobaric interferences, blanks, and laser ablation- and matrixinduced isotopic fractionation. By comparing raw $\mathrm{Fe}$ and $\mathrm{S}$ isotope ratios measured on standard minerals and calibrated against standard solutions, it was possible to determine the instrumental mass bias (i.e., isotope fractionation induced by laser ablation). Calibrated against the pure IRMM-14 solution, duplicated $\delta^{57} \mathrm{Fe}$ analysis of GAV-18 pyrite standard yielded 0.48 $\pm 0.22 \%$ o ( $2 \mathrm{sd}, n=13$ ), which is about $0.17 \%$ o lighter than bulk $\delta^{57} \mathrm{Fe}$ value determined at $0.65 \pm 0.14(2 \mathrm{sd}, n=2)$. As already discussed for $\mathrm{S}$ isotopes using similar experimental setup (i.e., raster mode, Craddock et al., 2008), the isotopic compositions of the GAV-18 standard determined with both methods were identical within analytical uncertainties. This indicates that laser ablation introduced isotope fractionations that were within the analytical uncertainties ( $\pm 0.2 \%$ at $2 \mathrm{sd})$.

To further evaluate whether $\mathrm{Fe}$ isotope analyses were potentially affected by the presence of $\mathrm{S}$ and $\mathrm{Si}$ impurities in $\mathrm{Fe}$ oxyhydroxides, we added $\mathrm{S}$ and $\mathrm{Si}$ at various concentrations to pure standard solutions. The results show that, after appropriate corrections with $\mathrm{Ni}$ isotopes, no bias could be detected up to $\mathrm{Si}$ and $\mathrm{S} / \mathrm{Fe}$ ratios $(\mathrm{g} / \mathrm{g})$ in solutions up to 0.7 and 2.5 , respectively (Figure S6).

Although most advanced femtosecond ablation techniques enable matrix-independent calibration for $\mathrm{Fe}$ isotope analysis (Horn et al., 2006), our laser ablation technique may potentially be prone to significant fractionation during ablation and matrix effects that affect our accuracy and precision. Hence, we compared the Fe-isotope data obtained by laser ablation MCICP-MS with Fe-isotope data acquired through conventional MC-ICPMS technique after microdrilling and complete chromatographic purification. We collected powder microsamples using a microdrill device (New Wave Micromill equipped with drill bit diameter of $700 \mu \mathrm{m}$ ) across the samples investigated by LA-MC-ICP-MS. Following the same protocols as for the bulk chimney samples (Rouxel et al., 2008a) we digested these micro-samples, separated $\mathrm{Fe}$ through anion-exchange chromatography procedure and measured $\mathrm{Fe}$ isotopes by MC-ICP-MS (Neptune, Thermo Scientific at Pole Spectrometry Ocean, Brest). The results on standards and comparison between laser-ablation and microdrilling techniques suggest that both approaches yield similar results within analytical uncertainties.

\section{RESULTS}

\section{K Vent Diffuser Site}

$\mathrm{K}$ Vent (Figures S1A,B) is an active diffuser site where active chimney spires (EPR-4053-M1-A1 and EPR-4053-M1A2; Figures S2A,B) and inactive chimney rubble (EPR-4053M3; Figure S2C) were collected. In the following paragraphs, for each of these samples, a description of the sample texture, $\mathrm{Fe}$ chemistry, and Fe (and in some cases S) isotopic composition is provided.

The seawater exposed surface of the actively diffusing spire (EPR-4053-M1-A1) is composed of an Fe-rich and Sdepleted zone underlain by a Si-rich layer (Figure 1A). Linear combination fitting (LCF) results for Fe XANES and EXAFS spectra from this sample are consistent with ferrihydrite; 2line and 6-line $\left[\mathrm{Fe}_{10} \mathrm{O}_{14}(\mathrm{OH})_{2}\right.$ idealized formula (Michel et al., 2007); Tables S3, S4]. The Fe-rich and S-depleted zone in the actively diffusing spire sample EPR-4053-M1-A2 is displayed in Figure 1B). The Fe XANES and EXAFS data for this sample are consistent with an $\mathrm{Fe}$ (III)-rich biogenic-like Fe oxyhydroxide phase with ferrihydrite contributions: either 2-line or 6-line satisfies the LCF. Both samples investigated are from the base of the active spire of K Vent (Figure S3).

Two seawater-exposed surfaces of the $\mathrm{K}$ Vent inactive rubble (EPR-4053-M3) are shown in Figures 1C,D. Both regions of the sample are characterized by complex interweaved layers of $\mathrm{Fe}(\mathrm{III}), \mathrm{Si}$, and sulfide. Petrographic observation and Xray fluorescence maps (Figure 2) show the co-occurrence of Fe oxyhydroxide, silica (mainly amorphous silica) and pyrite with often rounded and colloform textures. Pyrite spherules (about 50-100 $\mathrm{mm}$ diameter) are particularly common along former pyritized worm tubes that are partially filled by silica and $\mathrm{Fe}$ oxyhydroxides. The Fe XANES data from both regions indicate that the $\mathrm{Fe}$ (III) layers are composed of a biogeniclike Fe oxyhydroxide (40-60 mol\%; Table S3) and have varying contributions from goethite $(\alpha-\mathrm{FeOOH})$ or akaganeite $(\beta$ $\mathrm{FeOOH})$. Fits to Fe XANES and EXAFS data are in good agreement (Table S4). Locations of coupled Fe and S isotope measurements for chimney wall pyrite, as well as colloform and spherulitic pyrite, using laser ablation are also shown in Figure 2 


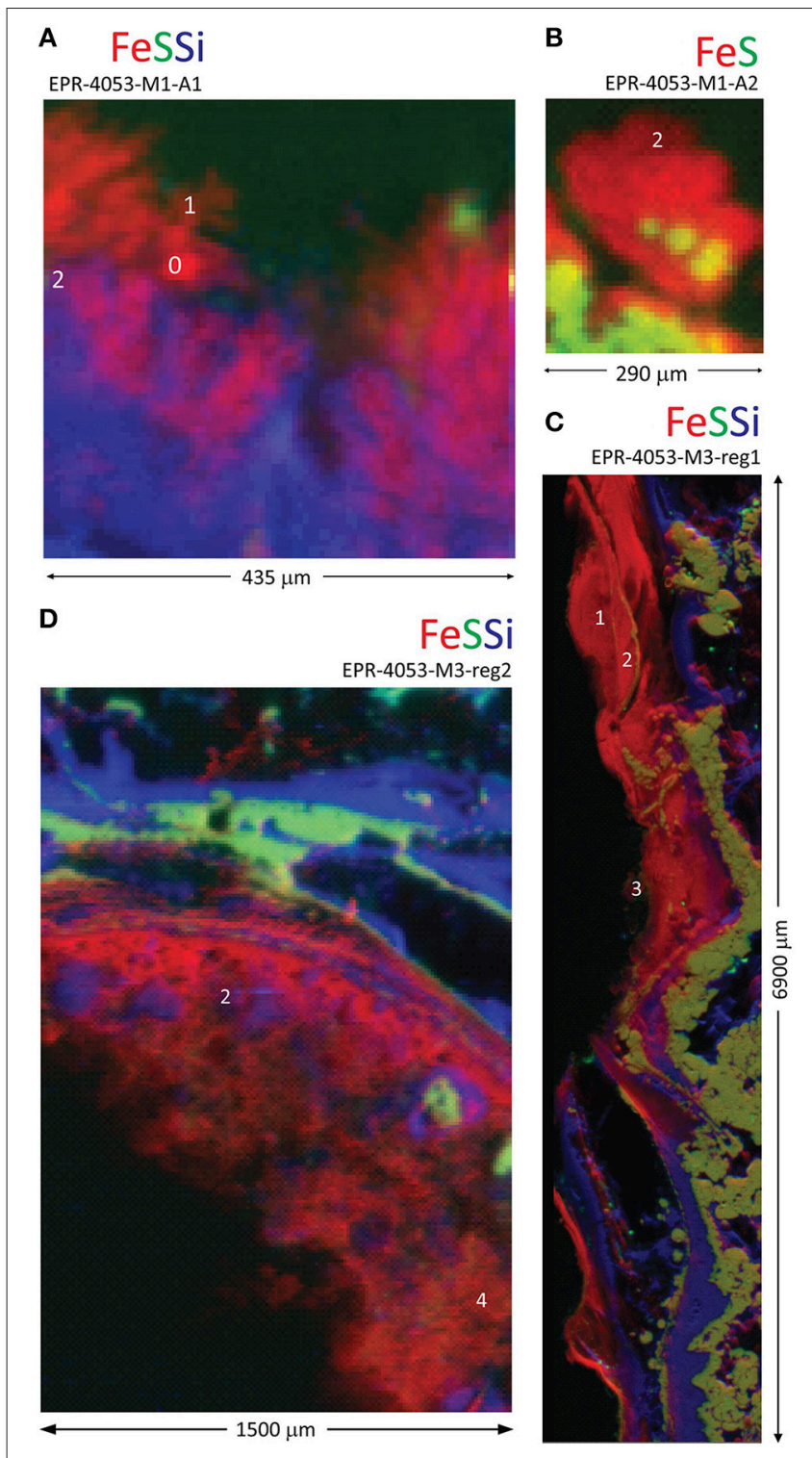

FIGURE 1 | Distribution of $\mathrm{Fe}, \mathrm{S}$, and $\mathrm{Si}$ in inactive spire and chimney rubble samples from $\mathbf{K}$ Vent. Red-green-blue (Fe-S-Si) tri-color X-ray fluorescence maps for (A) inactive spire (EPR-4053-M1-A1), (B) inactive spire (EPR-4053-M1-A2), (C) chimney rubble (EPR-4053-M3-reg1), and (D) chimney rubble (EPR-4053-M3-reg2). White numbers indicate locations for Fe X-ray absorption near edge structure (XANES; Table S3) or extended X-ray absorption fine structure (EXAFS; Table S4) data collection.

with results in Table S5. Results show relatively homogenous isotope values, with average $\delta^{57} \mathrm{Fe}=-2.0 \pm 1.0 \%$ o ( $2 \mathrm{sd}, n$ $=8$ ) and $\delta^{34} \mathrm{~S}=3.3 \pm 0.9 \%$ o ( $\left.2 \mathrm{sd}, n=8\right)$ which is globally consistent with bulk chimney pyrite values $\left(\delta^{57} \mathrm{Fe}=-1.49 \pm\right.$ $0.16 \%$ and $\delta^{34} \mathrm{~S}=1.4 \pm 0.2 \%$ ) (Rouxel et al., 2008a). Also in EPR-4053-M3-reg1, Fe oxyhyroxides occur in association with minor silica (Figure 2) forming a mm-thick external wall. Spatially resolved analyses using a microdrilling technique reveal a range of $\delta^{57} \mathrm{Fe}$ values from $-0.32 \pm 0.10 \%$ ( $2 \mathrm{sd}$ ) down to $0.8 \pm 0.14 \%$ o $(2 \mathrm{sd})$ which are similar, albeit slightly heavier, than laser ablation analysis ranging from $-0.44 \pm 0.14 \%$ o ( $2 \mathrm{sd})$ down to $-1.35 \pm 0.5 \%$ o (2 sd). Compared to colloform pyrite from the outer chimney wall, Fe oxyhydroxides show enrichments in heavy $\mathrm{Fe}$ isotopes by up to $2.3 \%$ (i.e., relative to ${ }^{57} \mathrm{Fe} /{ }^{54} \mathrm{Fe}$ ratios).

\section{Bio 9 Massive Sulfide Deposits}

Our sample set includes two massive sulfide deposits in the vicinity of Bio9 Vent (EPR-4057-M2 and EPR-4059M3; Figures S1C,D). Both deposits exhibit Fe-rich and Sdepleted zones at the seawater exposed surfaces with low (or undetectable) Si (Figure 3). The Fe XANES data for EPR4057-M2 are dominated by the Fe(III) oxyhydroxide goethite with lesser contributions of a biogenic-like Fe oxyhydroxide signature (Table S3). The goethite phase assignment is supported by Fe EXAFS (Table S4) and micro-probe X-ray diffraction (Figure S7). One Fe XANES location is consistent with the $\mathrm{Fe}$ (III) oxyhydroxide lepidocrocite (spot 7). Where $\mathrm{Fe}$ XANES and EXAFS observations overlap for this sample, the observations are in agreement (Table S4). The Fe XANES data for the seawater exposed portion of massive sulfide EPR-4059-M3 reveal heterogeneous Fe-bearing mineralogy: consistent with 2-line ferrihydrite, goethite, akaganeite, and secondary phyllosilicates ("clay" minerals; Table S3). Despite the complexity in Fe-bearing phases, the Fe-rich and S-depleted phases are predominantly $\mathrm{Fe}(\mathrm{III})$.

Light micrographs and X-ray fluorescence maps of region 1 of sample EPR-4057-M2 (Figure S8; Figure 4A) show a relatively sharp contact between the external layer (i.e., alteration crust composed essentially of Fe oxyhydroxides) and the pyrite-rich interior. Disseminated Fe oxyhydroxides also occur as coatings and void filling between pyrite grains suggesting partial pyrite alteration. In this region, average $\delta^{57} \mathrm{Fe}$ values by laser ablation analysis for Fe oxyhydroxides in the alteration layer and pyrite are $-1.93 \pm 0.20 \%$ o ( $2 \mathrm{sd}, n=6)$ and $-1.69 \pm 0.22 \%$ o ( $2 \mathrm{sd}, n$ $=4$ ), respectively. In other regions of the same sample similar average $\delta^{57} \mathrm{Fe}$ values for Fe oxyhydroxides $(-1.64 \pm 0.32 \%$ ) and pyrite $(-2.37 \pm 0.40$ and $-2.12 \pm 0.60 \%$ o $)$ are obtained (Table S6). Average $\delta^{57} \mathrm{Fe}$ values for pyrite are consistent with bulk values determined at $-2.58 \pm 0.09 \%$ (Rouxel et al., 2008a). However, differences in $\delta^{57} \mathrm{Fe}$ values from microdrilling another region of the sample are observed (region 3): $\delta^{57} \mathrm{Fe}$ values ranging from -0.25 to $-0.44 \%$ o for Fe oxyhydroxides and $-1.09 \%$ o for pyrite (Table S6). These results suggest significant isotope heterogeneity of pyrite in this sample and show that Fe oxhydroxides may have either similar or slightly heavier $\delta^{57} \mathrm{Fe}$ values relative to pyrite; which is in contrast with results obtained for sample EPR-4053-M3.

\section{Inactive Off-Axis Chimney}

An extinct, off-axis chimney structure (EPR-4059-M4) located $300 \mathrm{~m}$ east of the spreading center is part of our study (Figure S1E). Four regions of one grab sample show (Figures 4B, 5) that the sample is characterized by a complex interweave of $\mathrm{Fe}(\mathrm{III})$ - and Si-rich layers. The seawater-exposed portion of the sample had bright orange and yellow precipitates (Figure 6A) composed of biological material (Figures 6B,C). 


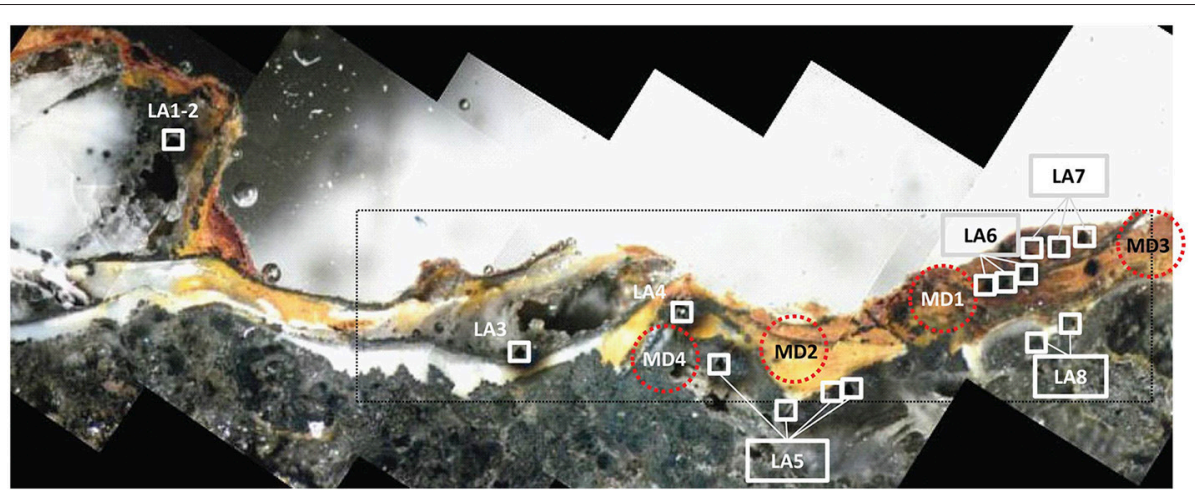

FIGURE 2 | Light microscope image for K Vent sample EPR-4053-M3-reg1. The area of the sample shown in Figure 1C is indicated by the black rectangle. Image is annotated with white boxes indicating laser ablation (LA) areas and red dashed circles indicating locations for micro-drilling (MD). Both laser ablation and micro-drilling produced samples for isotopic analysis (Table S5).

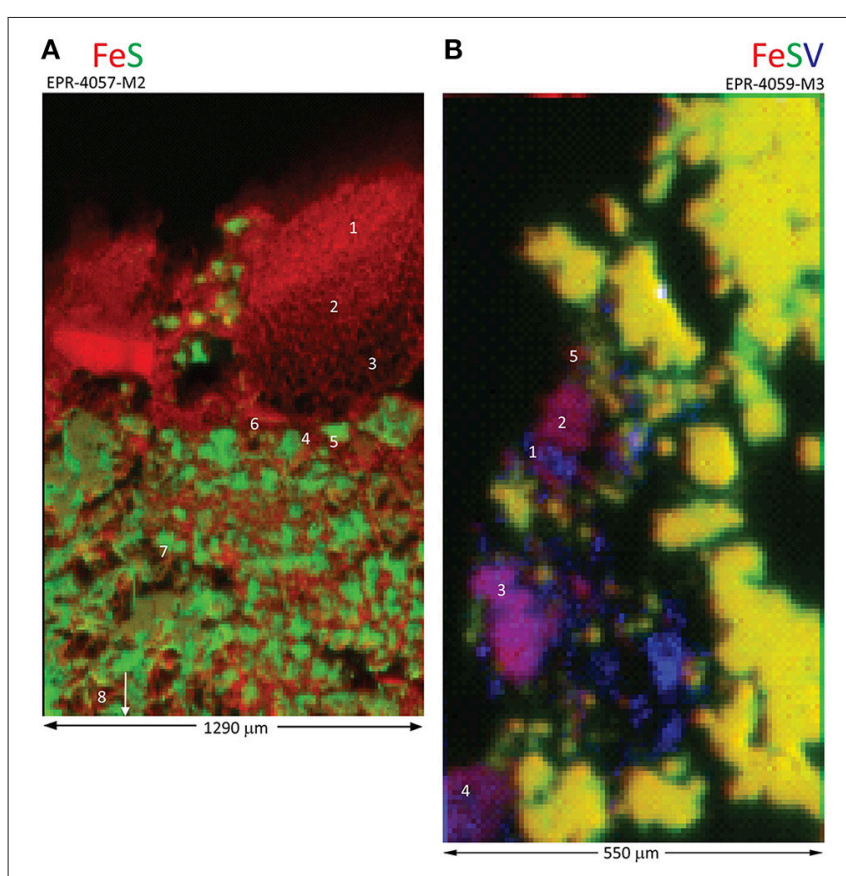

FIGURE 3 | Distribution of $\mathrm{Fe}, \mathrm{S}$, and V in massive sulfide deposits near Bio9 Vent. X-ray fluorescence maps for (A) EPR-4057-M2, and (B) red-green-blue (Fe-S-V) distribution for EPR-4059-M3. White numbers indicate locations for Fe X-ray absorption near edge structure (XANES) (Table S3) or extended X-ray absorption fine structure (EXAFS) (Table S4) data collection.

In region 1 , the sulfides (pyrite) are overlain by a Si-rich layer, then an As-rich layer, and finally a Fe(III)-rich layer exposed to seawater(Figure 5A, spot 1; Table S3). The Fe XANES data indicate that the $\mathrm{Fe}(\mathrm{III})$ layer in region 1 was $70-100 \mathrm{~mol} \%$ biogenic-like $\mathrm{Fe}$ oxyhydroxide with varying contributions from goethite and phyllosilicate (Figure 5A; spot5; Table S3). Laser ablation analyses of pyrite yield average $\delta^{57} \mathrm{Fe}$ values of $-2.9 \pm$ $0.7 \%$ ( $2 \mathrm{sd}, n=7$; Table S7; Figure 7A), which is within the range of $\delta^{57} \mathrm{Fe}$ values for the bulk sample $\left(\delta^{57} \mathrm{Fe}=-2.33\right.$ and

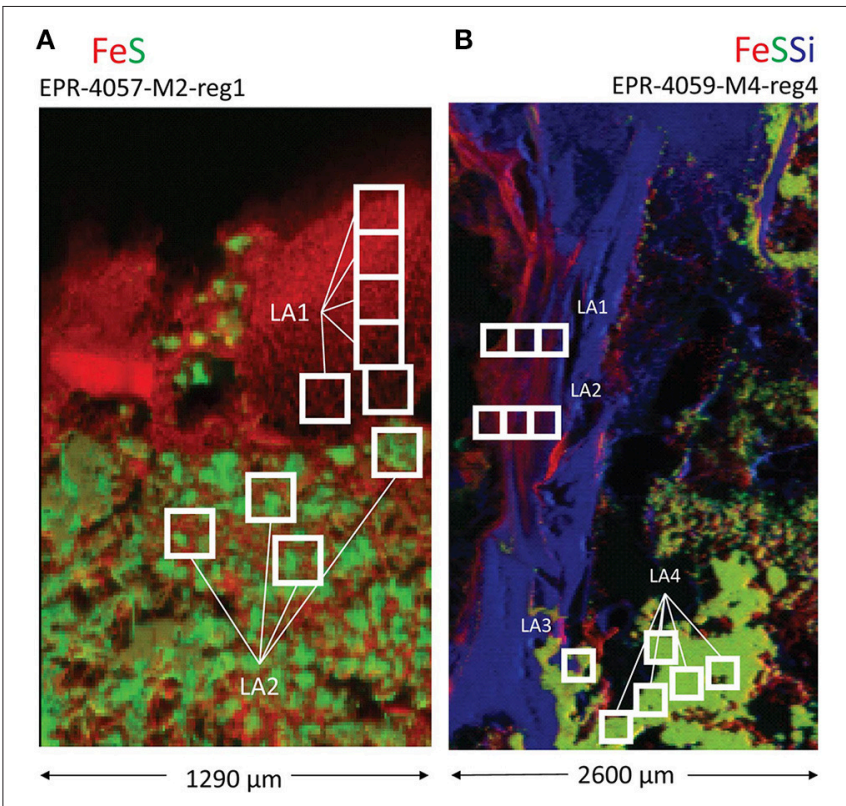

FIGURE 4 | Locations of laser ablation (LA) sampling for (A) a massive sulfide sample (EPR-4057-M2-reg1) and (B) an extinct, off-axis

chimney sample (EPR-4059-M4-reg4). X-ray fluorescence (XRF) maps are annotated with white boxes indicating laser ablation areas corresponding to isotopic data in Tables S6, S7.

$-2.94 \%$ ) (Rouxel et al., 2008a). Iron isotope analysis of 3 areas enriched in Fe oxyhydroxides show contrasting Fe isotope values: (i) the external layer enriched in As has Fe isotope values similar to pyrite, with $\delta^{57} \mathrm{Fe}=-2.1 \pm 0.5 \%$ o $(2 \mathrm{sd}, n=4)$; (ii) the internal layer between pyrite and the external As-Fe-Si external crust shows very light $\mathrm{Fe}$ isotope values, with $\delta^{57} \mathrm{Fe}=-4.6 \pm 0.3 \%$ o ( 2 sd, $n=4$ ) which is even lighter than pyrite values; and (iii) average Fe oxyhydroxide layer (i.e., sampled by microdrilling) adjacent to the two others has a heavier value, $\delta^{57} \mathrm{Fe}=-0.95 \pm$ $0.04 \%$. 


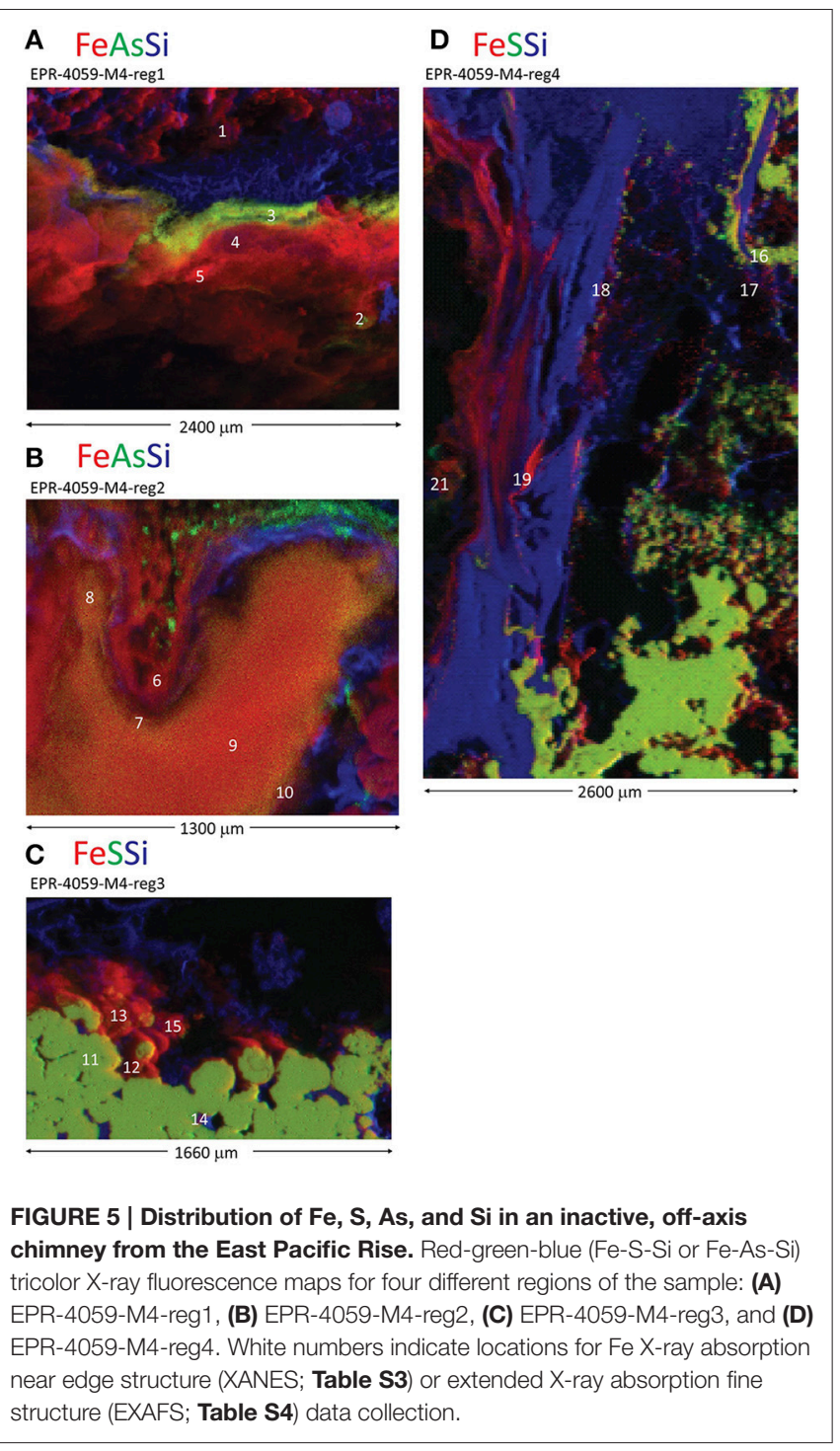

Region 2 is internal to the grab sample and has Fe(III)-, As-, and S-rich layers (Figure 5B). The Fe oxyhydroxides in this region do not occur as a well-defined external crust along the outside layer of the chimney wall, but rather as filling material in a chimney cavity probably exposed to ambient seawater. The Fe XANES for the Fe(III)-rich materials are consistent with biogenic-like $\mathrm{Fe}$ oxyhydroxide, 2-line ferrihydrite, and goethite (Table S3). For region 2 spot 21, the best one component fit to the Fe EXAFS data is biogenic-like Fe oxyhydroxide (Table S4), and the best two component fit is biogenic-like Fe oxyhydroxide plus phyllosilicate. For the EXAFS LCF, the one component fit is chosen based on the a priori requirement that additional fit components require a $10 \%$ or greater improvement in the normalized sum square (NSS) parameter. The EXAFS results are overall consistent with the Fe XANES fitting. This region shows the lightest $\mathrm{Fe}$ isotope values obtained so far in natural samples with $\delta^{57} \mathrm{Fe}$ values obtained by laser ablation ranging from $-6.9 \pm 0.7 \%$ o $(2 \mathrm{sd}, n=4)$ to $-1.6 \pm 0.3 \%$ o
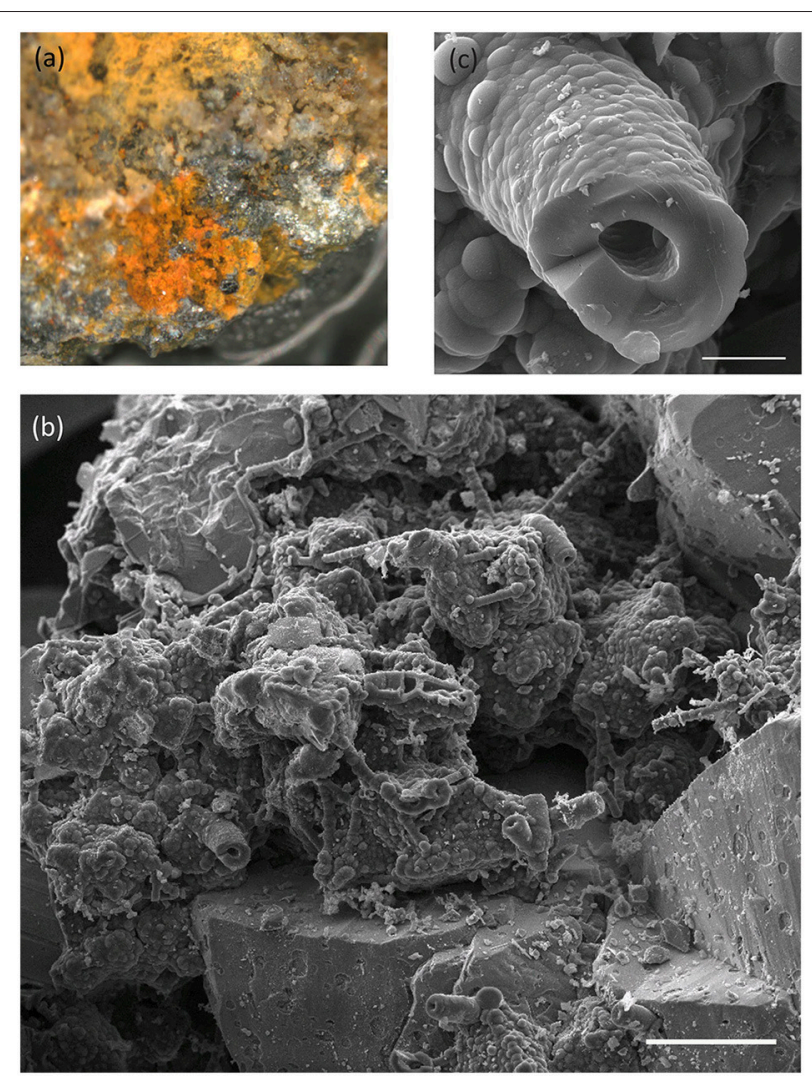

FIGURE 6 | Images of seawater exposed surface of East Pacific Rise off-axis, extinct chimney sample (EPR-4059-M4). (A) Binocular light microscope image of sample showing fine-grained orange and yellow alteration products. Field of view is $\sim 0.5 \mathrm{~cm}$. (B) Representative scanning electron microscope (SEM) image highlighting the abundance of biological materials. Scale bar is $100 \mu \mathrm{m}$. (C) A higher magnification image of a stalk-type structure prevalent in these materials. Scale bar is $10 \mu \mathrm{m}$.

while values from microdrilling ranging from -4.73 to $-1.83 \%$ o (Figure 7B; Table S7). This demonstrates a great heterogeneity of Fe isotopes values, characterized by $\delta^{57} \mathrm{Fe}$ values both lighter and heavier than pyrite values from the adjacent area $\left(\delta^{57} \mathrm{Fe}=\right.$ $-2.54 \%$ and $-3.32 \pm 0.4 \%$, microdrilling and laser ablation, respectively).

Region 3 has a thin layer of Fe(III) overlaying sulfides, with the seawater-exposed edge covered by a thin Si-rich layer (Figure 5C). The Fe XANES from the sulfide-Fe(III) transition indicate a variety of $\mathrm{Fe}$ (III)-bearing phases including biogenic-like $\mathrm{Fe}$ oxyhydroxide, goethite, and phyllosilicate (Table S3). No Fe isotope analysis was obtained from this region.

In region 4 , sulfides (pyrite) are overlain by $\mathrm{Si}$ - and then Fe(III)-rich layers (Figure 5D, spot 16; Table S3). The Fe XANES indicate that the $\mathrm{Fe}(\mathrm{III})$-bearing phases with spectral signatures consistent with 2-line ferrihydrite, goethite, akaganeite, and phyllosilicate (Table S3). Iron isotope values for pyrite obtained by laser ablation are relatively homogenous, with $\delta^{57} \mathrm{Fe}=-3.25$ $\pm 0.7 \%$ o (2 sd, $n=12$ ), which is similar within uncertainties 


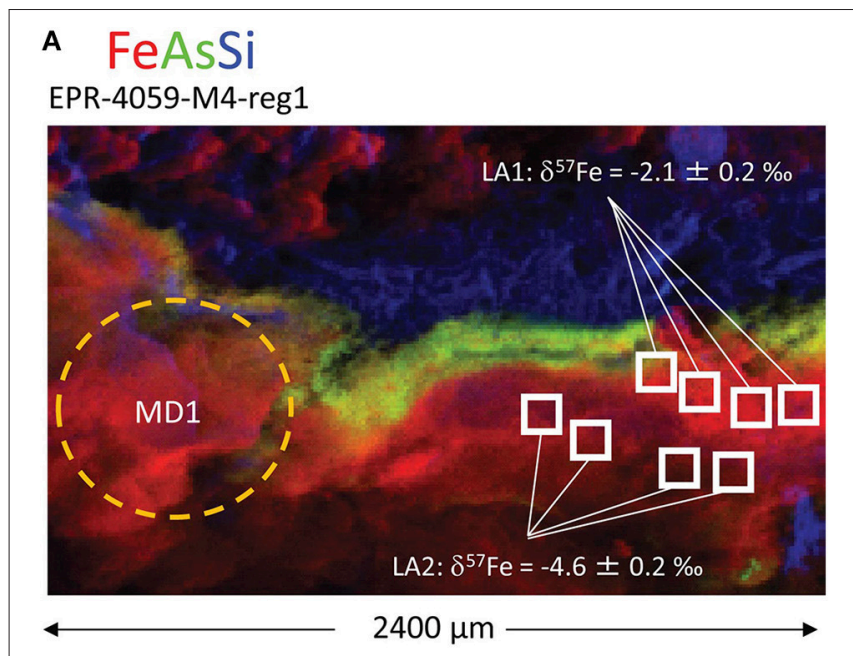

B FeSSi

EPR-4059-M4-reg2

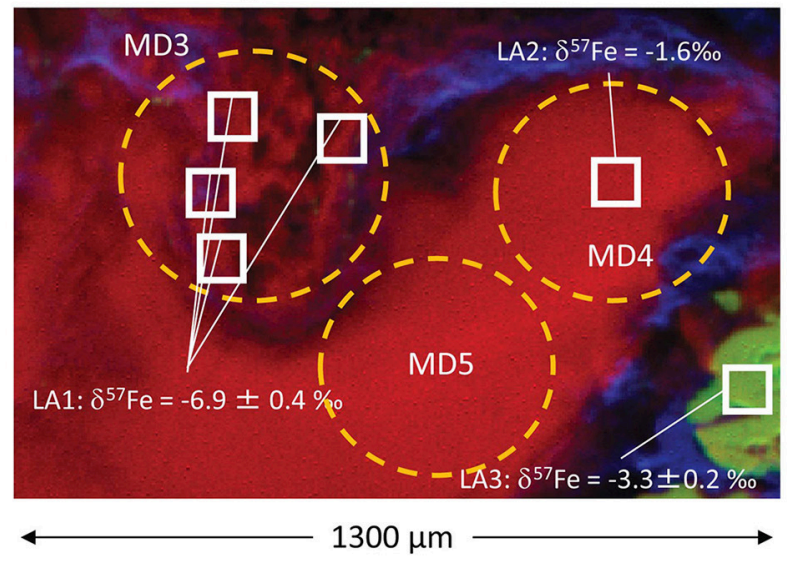

FIGURE 7 | Locations of laser ablation (LA) and micro-drilling (MD) samples for two regions within the extinct, off-axis chimney: (A) EPR-4059-M4-reg1 and (B) EPR-4059-M4-reg2. Both laser ablation and micro-drilling produced samples for isotopic analysis (Table S7).

to the lower values obtained for microdrilled pyrite $\left(\delta^{57} \mathrm{Fe}=\right.$ $-3.28 \%$ ) and bulk pyrite using $\left(\delta^{57} \mathrm{Fe}=-2.33\right.$ and $-2.94 \%$; Table S7; Figure 4B) (Rouxel et al., 2008a). Iron oxyhydroxides overlying the Si-rich layer show larger spread of $\delta^{57} \mathrm{Fe}$ values, from $-2.71 \pm 0.12 \%$ o (microdrilling) to $-4.1 \pm 0.8 \%$ o $(n=3$; laser ablation).

\section{Diversity of Iron-Bearing Phases and Co-Located Elements}

A summary of the linear least-squares fitting of spectra to combinations of reference spectra (LCF) is provided in Table S3. Principal component analysis (PCA) for the 43 Fe XANES spectra is consistent with eight different Fe species; as indicated by the minimum of the IND parameter (Manceau et al., 2002). The LCF results for Fe XANES spectra are in agreement with the PCA assessment of eight different Fe species among the 1st and

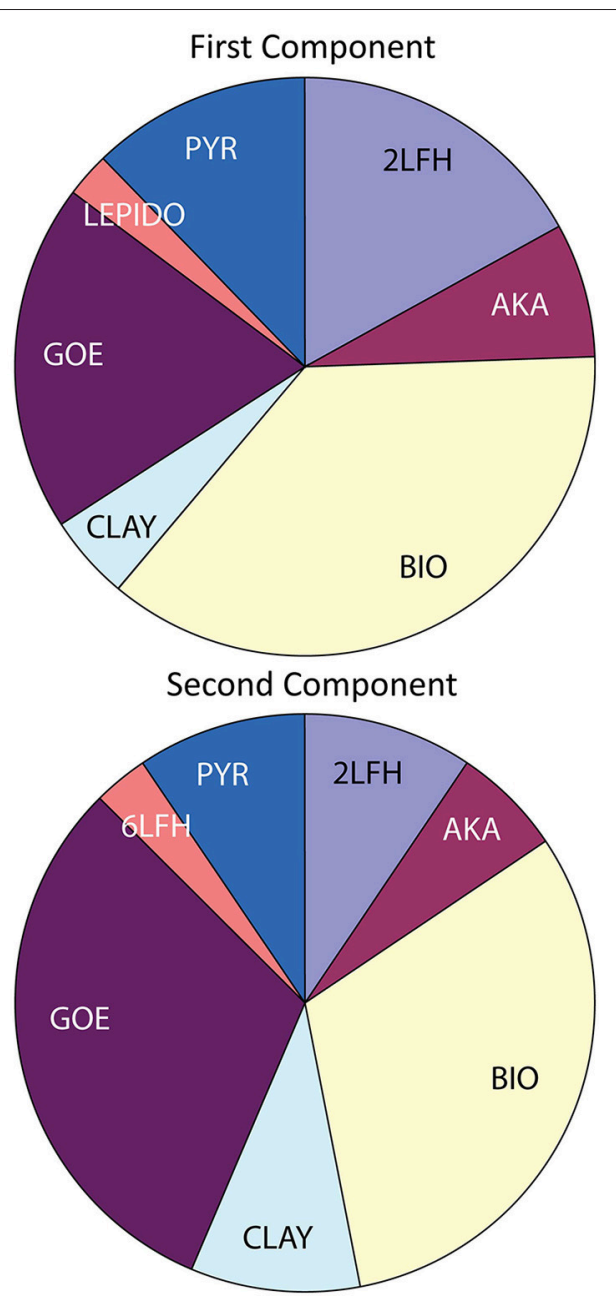

FIGURE 8 | Summary of linear combination fitting (LCF) results for Fe XANES spectra. Acronyms described in Table $\mathbf{S} 2$ and full data set displayed in Table S3.

2nd fit components (Table S3; Figure 8). For 78\% of the spectra, a second component in the fit is justified by a $>10 \%$ improvement of the NSS parameter. For $32 \%$ of the spectra, a 3 rd component is justified. These results indicate that in most cases, even at the 10 -micron scale, a mixture of Fe-bearing minerals is present. The spectral components supported by PCA, target transformation analysis (TTA), and LCF are: pyrite (PYR); biogenic Fe oxyhydroxide (BIO); lepidocrocite (LEPIDO); 6-line ferrihydrite (6LFH); 2-line ferrihydrite (2LFH); nontronite (NONT); smectite (CLAY-S); goethite (GOE); and akaganeite (AKA) (Table S2). Note that Fe-bearing phyllosilicates nontronite and smectite components are binned as a single "clay" category (Figure 8). Three additional minor Fe-species (never exceeding 13 mole\%) are supported by LCF as 3rd components: chromite (CHROM); richterite (RICHT); and pervoskite (PEROV). These fit results indicate that some additional $\mathrm{Fe}$ (II) is present in the sample, but are not interpreted as firm evidence for the specific mineral form. 


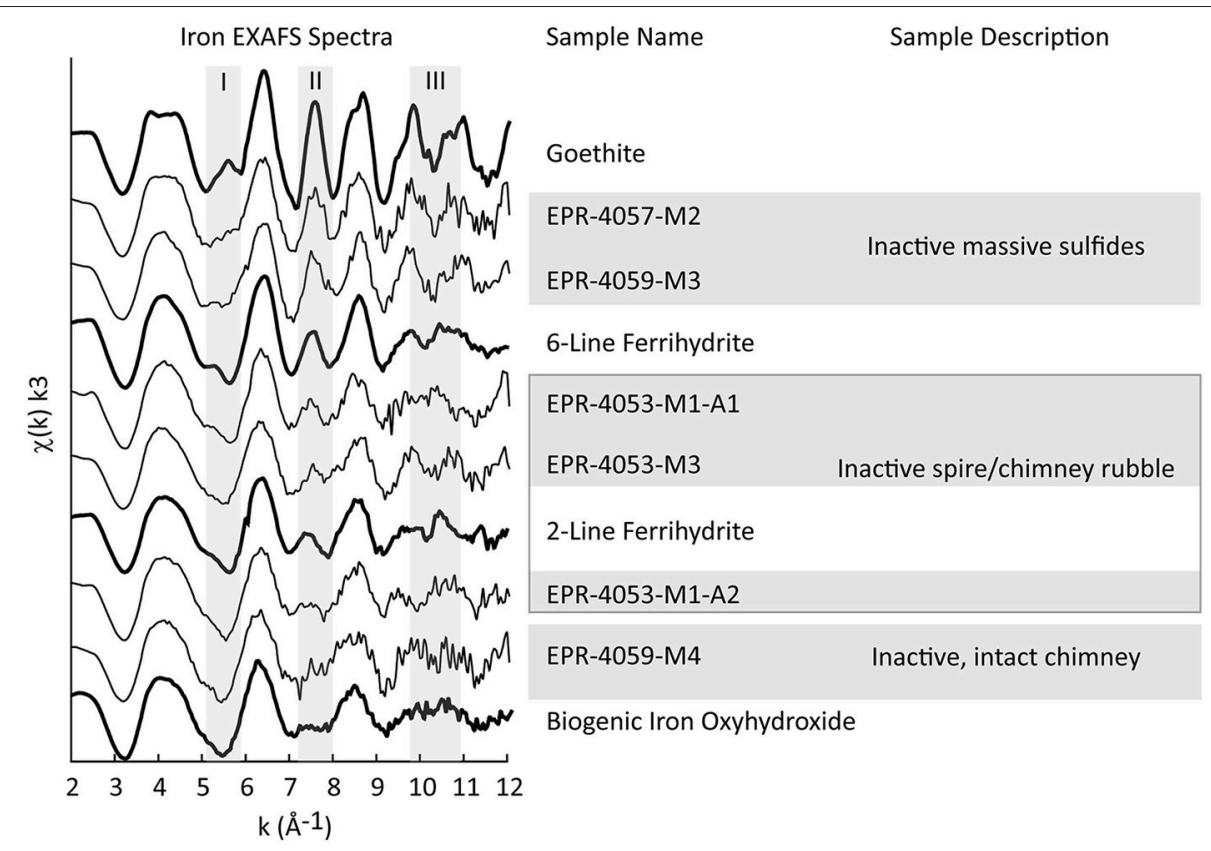

FIGURE 9 | Iron EXAFS spectra for EPR samples (fine lines) are plotted with spectra from Fe-bearing reference materials (bold lines). The location of Fe EXAFS data collection is recorded in Table $\mathbf{S} 4$ with asterisks and annotated in Figures 1, 3, 5.

\section{Comparison of Iron XANES and EXAFS Data}

A full continuum of Fe oxyhydroxide phases, supported by $\mathrm{Fe}$ EXAFS data, are observed for the EPR sulfide deposits, from BIO-like phases lacking long-range structural order to wellcrystallized goethite (Figure 9). Like the Fe XANES, Fe EXAFS spectra are subjected to LCF with reference spectra. Shell-byshell fitting of the EXAFS data was not attempted due to the relatively short $\mathrm{k}$-space range of the useable data (ca. $11 \AA^{-1}$ ). The results of the fitting are summarized in Table S4, and the LCFs are plotted with the EXAFS data in Figure S9. The fits to the EXAFS data agree well with XANES fits for the same locations on the samples. For example, the Fe EXAFS data from sample EPR-4057-M2 is best fit by $67 \%$ goethite (GOE) and 39\% biogenic Fe oxyhydroxide (BIO) references. In this sample location, microprobe XRD was used to verify that goethite was present (Figure S7); this is an important methodological confirmation that the goethite reference spectrum is representative of goethite in the sample. The corresponding fit to the much shorter Fe XANES data region yields $62 \%$ goethite and $34 \%$ BIO. The comparisons of XANES and EXAFS data also show that spectroscopically similar phases can be difficult to distinguish using LCF. For example, the Fe EXAFS data from sample EPR4053-M1-A2 is best fit by 55\% BIO and 34\% 6-line ferrihydrite (6LFH), while the corresponding Fe XANES data fit yields $47 \%$ $\mathrm{BIO}$ and 52\% 2-line ferrihydrite (2LFH).

\section{Comparison of Iron Isotope Compositions}

The EPR chimney samples that exhibit complex interweaved layers of $\mathrm{Fe}(\mathrm{III}), \mathrm{Si}$, and sulfide have a larger range of $\delta^{57} \mathrm{Fe}$ values relative to massive sulfides (e.g., EPR-4057-M2). When Fe oxyhydroxides occur as filling materials within the chimney wall or as outside layer crusts in association with Si-rich material, enrichments in both heavy and light Fe isotopes relative to pyrite are possible. The range of values $\delta^{57} \mathrm{Fe}$ is up to $6 \%$ which enlarges not only the range of Fe isotopes measured in hydrothermal vent environments (Rouxel et al., 2008a) but also in marine sediments (Severmann et al., 2006; Johnson et al., 2008; Rouxel et al., 2008b). In most cases, $\mathrm{Fe}$-oxyhydroxides are enriched in light $\mathrm{Fe}$ isotopes relative to vent fluid sources (Figure 10).

\section{DISCUSSION}

\section{Iron Isotope Systematics}

Significant variability of $\mathrm{Fe}$ isotope composition in (oxyhydr)oxide precipitates is expected when $\mathrm{Fe}(\mathrm{II})$ is partially oxidized in conditions with slow rates of oxidation. Microbiological experiments have shown that $\mathrm{Fe}$ isotope fractionations are produced during dissimilatory Fe(III) reduction (Beard et al., 2003b; Icopini et al., 2004; Johnson and Beard, 2005) and anaerobic photosynthetic Fe(II) oxidation (Croal et al., 2004; Swanner et al., 2015). Iron isotopes can also be fractionated by abiotic $\mathrm{Fe}$ (II) oxidation, precipitation of ferric hydroxides (Bullen et al., 2001; Beard et al., 2010), and by sorption of aqueous $\mathrm{Fe}(\mathrm{II})$ onto $\mathrm{Fe}$ oxyhydroxides (Icopini et al., 2004; Wu et al., 2012). The largest equilibrium isotope fractionations $\left(\sim 4.5 \%\right.$ o in ${ }^{57} \mathrm{Fe} /{ }^{54} \mathrm{Fe}$ ratios) observed and theoretically calculated are for coexisting $\mathrm{Fe}(\mathrm{III})$ and $\mathrm{Fe}$ (II) aqueous species (Welch et al., 2003; Anbar et al., 2005). Hence, in view of the variety of fractionating processes during Fe redox 


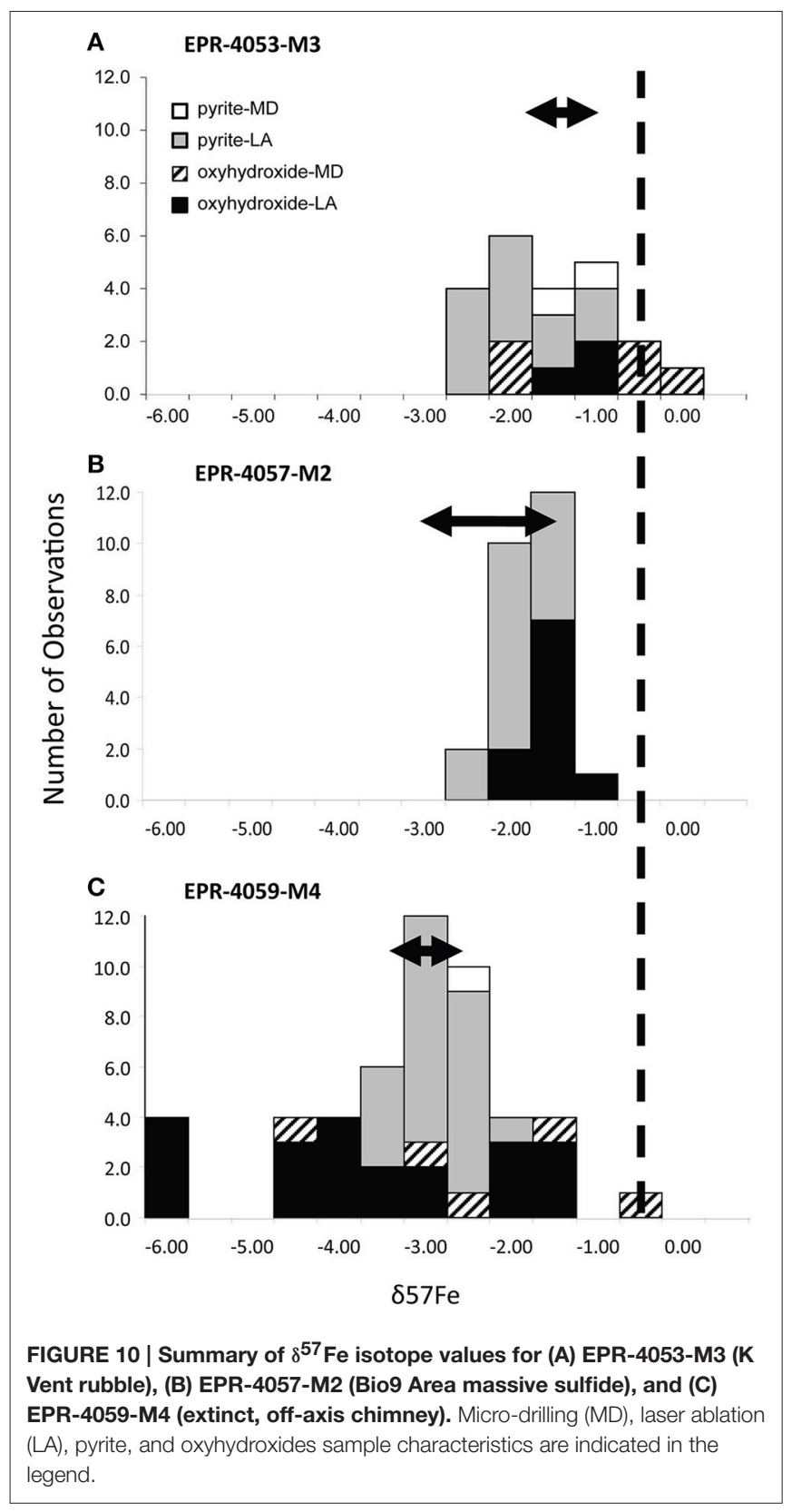

changes, it is not surprising that marked variations in Fe-isotope composition have been observed in Fe-rich marine environments (Severmann et al., 2006; Rouxel et al., 2008b). Large variations are also reported in banded iron formations (Johnson et al., 2003; Rouxel et al., 2005; Dauphas and Rouxel, 2006; Planavsky et al., 2012), hydrothermal fluids and precipitates (Sharma et al., 2001; Beard et al., 2003a; Rouxel et al., 2003, 2004), and ancient seafloor hydrothermal Fe-Si deposits (Planavsky et al., 2012; Moeller et al., 2014). Iron (oxyhydr)oxide particles within near-vent (buoyant) hydrothermal plumes at the Rainbow hydrothermal field (Mid Atlantic Ridge) have variable $\delta^{57} \mathrm{Fe}$ values $(0.15$ to $1.65 \%$ o $)$ relative to the original vent fluid, consistent with fractionation during partial oxidation of $\mathrm{Fe}(\mathrm{II}) a q$ to $\mathrm{Fe}(\mathrm{III})$ aq in seawater (Severmann et al., 2004). In contrast, Fe (oxyhydr)oxide-rich sediments precipitated from non-buoyant hydrothermal plumes have $\delta^{57} \mathrm{Fe}$ values that are indistinguishable from that of high-temperature hydrothermal fluids (Severmann et al., 2004). In a more recent study, low-temperature $\mathrm{Fe}$ (oxyhydr)oxide deposits from the Jan Mayen hydrothermal vent fields Norwegian-Greenland Sea yielded very light $\delta^{57} \mathrm{Fe}$ values down to $-2.8 \%$ o (Moeller et al., 2014). These values are indistinguishable from low-temperature hydrothermal fluids from which they precipitated, suggesting that hydrothermal vent fluid underwent significant partial $\mathrm{Fe}$ (II) oxidation below seafloor leading to isotopically light $\mathrm{Fe}$ values for $\mathrm{Fe}(\mathrm{II})$, as previously proposed (Rouxel et al., 2003).

In our study, $\delta^{57} \mathrm{Fe}$ values for Fe oxyhydroxides of the chimney wall are both heavier and lighter than the coeval pyrite or hydrothermal fluids. We propose that a reservoir effect is created during partial $\mathrm{Fe}(\mathrm{II})$ oxidation and can explain the diversity of values: (1) heavier values are consistent with small extent of $\mathrm{Fe}$ (II) oxidation; (2) lighter values are consistent with a greater extent of $\mathrm{Fe}(\mathrm{II})$ oxidation; and (3) lightest values are consistent with loss of $\mathrm{Fe}$ oxyhydroxides along a flow path (open system Fe oxidation) (Dauphas and Rouxel, 2006; Moeller et al., 2014). Extremely light $\mathrm{Fe}$ isotope values can be attained through Rayleigh-type fractionation and could explain the $\delta^{57} \mathrm{Fe}$ values, as low as $-7 \%$, we observe for $\mathrm{Fe}$ oxyhydroxides in sample EPR-4059-M4 (Figure 10C). Such partial Fe(II) oxidation probably required micro-aerobic conditions in which the rate of $\mathrm{Fe}(\mathrm{II})$ oxidation is slow enough to generate high variability of $\delta^{57} \mathrm{Fe}$ values. Considering that such conditions are also favorable for the growth of $\mathrm{Fe}$-oxidizing microorganisms (Druschel et al., 2008), the involvement of microorganisms in the $\mathrm{Fe}$ transformation pathways is likely. However, biotic Fe oxidation is not demonstrated in the present case because abiotic Fe oxidation can also produce these Fe isotope fractionation factors.

\section{Iron Transformation Pathways in Sulfide Mineral Deposits}

\section{Summary of Transformation Pathways}

The main goal of this study is to describe the Fe transformation pathways in natural sulfide mineral deposits at the seafloor, and examine the transformation products for indications or markers of biological activity. The hydrothermally inactive sulfide deposits of the EPR $9-10^{\circ} \mathrm{N}$ are known to host microbial communities with the genetic potential to alter $\mathrm{Fe}$ - and Sbearing minerals through redox reactions (Sylvan et al., 2012; Toner et al., 2013). Our investigation of the EPR sulfide deposits indicates that the alteration products are generated by at least four different pathways. Each pathway can be complete and quantitative, leading to an isotopic signature similar to the source $\mathrm{Fe}$, or partial, leading to isotopic fractionation:

(Pathway 1) direct precipitation of $\mathrm{Fe}(\mathrm{II}) a q$, to form primary sulfide minerals, from hydrothermal fluids in zones of mixing between vent fluids and seawater;

(Pathway 2) precipitation of Fe(II)aq, to form sulfide minerals, from $\mathrm{Fe}$ (III) reduction in zones of mixing between vent fluids and seawater; 
(Pathway 3) direct oxidation of Fe(II)aq from hydrothermal fluids, to form $\mathrm{Fe}$ (III) precipitates, in zones of mixing between vent fluids and seawater; and

(Pathway 4) oxidative alteration of pre-existing sulfide minerals to form $\mathrm{Fe}(\mathrm{III})$ precipitates.

\section{Pathways Created by Vent Fluid-Seawater Mixing}

In several sulfide deposits at the EPR, we observe layered zones of $\mathrm{Fe}(\mathrm{III})-, \mathrm{Si}-$, and sulfide-rich precipitates that are consistent with cooling vent fluids and low redox potential (e.g., Figures 1A,D,C, 5). The precipitation of pyrite in the exterior chimney wall is probably a late-stage phenomenon reflecting a different pathway of mineral formation than the coarse-grained to euhedral pyrite composing the chimney wall. In many cases, we observe colloform and spherulitic pyrite textures on the chimney exterior in association with amorphous silica and often lining former worm tubes. Fine-grained to colloform pyrite with minor sphalerite may occur along fossil worm tubes (formed probably by Alvinella) (Little et al., 2007; Rouxel et al., 2008a). As discussed by Xu and Scott, 2005, spherulitic and colloform textures of pyrite reflect rapid crystallization (i.e., disequilibrium) with cooling caused by mixing between hot vent fluid and cold ambient seawater. Overall, for our samples, the texture and morphology of these pyrite-Si-oxyhydroxide zones is highly variable; we speculate that this is caused primarily by the wide range of fluid flow and redox regimes created in actively venting chimneys. For many of our samples, pyrite lined fossil worm tubes exhibit $\delta^{34} \mathrm{~S}$ and $\delta^{57} \mathrm{Fe}$ values (4.3 to 3.0 and -1.8 to $-1.2 \%$, respectively) typical of bulk pyrite from the chimney wall (Rouxel et al., 2008b), which is consistent with direct precipitation from hydrothermal fluids (Pathway 1).

In addition to Pathway 1 , the presence of pyrite within layered zones of $\mathrm{Fe}$ (III)-, Si-, and sulfide-rich precipitates could be caused by reductive processes in the mixing zone (Pathway 2). For example, pyrite forming at low-temperature and in an open system in contact with sulfate-rich seawater creates the potential for microbial sulfate and $\mathrm{Fe}(\mathrm{III})$ reduction. This possibility has been proposed from studies of microbial diversity in hydrothermal chimneys (Callac et al., 2015), as well as metabolic energetic calculations (Amend et al., 2011). Sulfur isotope studies show the contribution of microbial sulfate reduction and sulfide formation at mid-oceanic ridges (Peters et al., 2010); however, a robust $\mathrm{S}$ isotope biosignature in hydrothermal chimney environments has not been demonstrated. Our results provide strong evidence for secondary and late-stage pyrite formation along the outside wall of the chimneys due to vent fluid-seawater mixing. This interpretation, based on isotope data, Fe speciation, and mineral textures, is also consistent with the observed enrichment in silica. In general, silica precipitation in seafloor hydrothermal chimneys requires some degree of conductive cooling due to the solubility of amorphous $\mathrm{Si}$ in simple mixing between hydrothermal fluids and seawater (Hannington et al., 1995).

Iron oxyhydroxides may also form in low-oxygen environments during hydrothermal-fluid mixing, although the expected slow rate of Fe oxidation in dilute hydrothermal fluids may limit the accumulation of $\mathrm{Fe}$ oxyhydroxides in the absence of microbial mediation. Localized $\mathrm{Si}$ and As enrichments within the $\mathrm{Fe}$ oxyhydroxides is common for our samples (Figures 1A,C,D, 5A-D). In many cases, the layered $\mathrm{Fe}(\mathrm{III})$-, $\mathrm{Si}-$, and sulfide-rich zones exhibit $\delta^{57} \mathrm{Fe}$ values that are consistently lighter than hydrothermal vent fluids (Figure 10). This observation cannot be explained by either partial or quantitative $\mathrm{Fe}$ (II) oxidation because the resulting Fe(III) should be enriched in heavy $\mathrm{Fe}$ isotopes relative to $\mathrm{Fe}(\mathrm{II})$, regardless of the mechanism and extent of Fe(II) oxidation. Therefore, it is likely that these Fe oxyhydroxides formed through a combination of quantitative oxidation of vent fluid Fe(II) (Pathway 3) and alteration (i.e., oxidation) of pyrite characterized by much lighter $\delta^{57} \mathrm{Fe}$ values than vent fluids (Pathway 4 ).

In sample EPR-4053-M3-reg1 (Figure 2), $\delta^{57} \mathrm{Fe}$ values are consistent with either partial oxidation of pyrite (partial Pathway 4) or direct and quantitative oxidation of late-stage vent fluid $\mathrm{Fe}(\mathrm{II})$ (Pathway 3). The $\delta^{57} \mathrm{Fe}$ values of the $\mathrm{Fe}$ oxyhydroxides range from -0.32 to $-1.59 \%$ which is heavier than associated pyrite by up to $2.3 \%$ but also within the range expected for hydrothermal vent fluids, especially lowtemperature or late-stage vent fluids (Rouxel et al., 2008a; Moeller et al., 2014). In contrast, sample EPR-4059-M4-reg2 (Figure 7B) exhibits very light $\mathrm{Fe}$ isotope values for the $\mathrm{Fe}$ oxyhydroxides, which are up to $4.7 \%$ lighter than associated pyrite. These data cannot be explained by simple mixing between $\mathrm{Fe}$ (III) derived from local sulfide (pyrite) oxidation and $\mathrm{Fe}(\mathrm{II})$ from vent fluid. During partial Fe(II) oxidation, the remaining $\mathrm{Fe}$ (II) in solution is expected to become isotopically lighter due to the precipitation of isotopically heavy $\mathrm{Fe}$ oxyhydroxide (partial Pathway 3). This mechanism, often referred to as a reservoir effect, has been shown to lead to isotopically light $\mathrm{Fe}(\mathrm{II})$ in sediment porewater $\left(\delta^{57} \mathrm{Fe}\right.$ down to $-7.38 \%$ ) (Rouxel et al., 2008a) and likely occurs within cavities of hydrothermal chimneys. The fact that isotopically light $\mathrm{Fe}$ oxyhydroxides occur in association with significant Si enrichment (e.g., EPR-4059-M4-reg4; Figure 4B) and filling cavities of the chimney wall (EPR-4059-M4-reg2; Figure 7B) is consistent with this assumption. In this case, $\mathrm{Fe}(\mathrm{II})$ released during pyrite alteration (Pathway 4) or late-stage hydrothermal fluid undergoing partial oxidation in the chimney wall (partial Pathway 3), leads to the formation of isotopically light Fe(II) diffusing out of the chimney wall and ultimately precipitating as Fe oxyhydroxide.

\section{Pathways Created by Complete and Direct Oxidation}

In contrast to the $\mathrm{Fe}$ transformation pathways discussed in section Pathways Created by Vent Fluid-Seawater Mixing, the two massive sulfide deposits exhibit a simpler set of Fe reactions. For the EPR-4057-M2-reg1, the $\delta^{57} \mathrm{Fe}$ values are very close to Fe in unaltered pyrite $(-1.93 \pm 0.20$ vs. $-1.69 \pm 0.11 \%$ ), and are consistent with direct and complete oxidation of pyrite$\mathrm{Fe}$ to goethite-Fe (Pathway 4; Figure 4A). While the incipient Fe oxyhydroxide phase is not known in this case, a shortterm ( 2 months) chimney incubation study at the Juan de Fuca Ridge indicates the possibility of a biogenic-like Fe oxyhydroxide incipient phase (Toner et al., 2009b). The fact that the Fe oxyhydroxide is primarily goethite, with no co-located Si or As, is 
suggestive of transformation of the initial precipitation products to the stable goethite phase over time in ambient deep ocean waters.

\section{CONCLUSIONS}

One of the main objectives of the present study is to determine whether alteration materials associated with seafloor sulfide deposits possess mineralogical or stable isotope biosignatures. In essence, we want to know the reactants, mechanisms, and products for reactions involving Fe. In light of the microbial community data (Sylvan et al., 2012; Toner et al., 2013), textural complexity noted in hand specimens (Rouxel et al., 2008a), and spatial scale of mineralogical variability in petrographic sections (this work), we chose a spatially resolved spectroscopic and isotopic approach to the study of the EPR sulfides. The spectroscopic approach provides the reaction products (and in some cases reactants) through measurement of the chemical form of $\mathrm{Fe}$, as well as the identity of co-located elements: while the isotopic approach provides the source-Fe reactant(s) and the extent of the reaction. The application of these complementary tools at the 10-50 micron spatial scale certainly must have averaged over finer submicron geochemical information. However, the spatial scale of investigation did allow us to describe the diversity of mineral forms and isotopic signatures intrinsic to these sulfides, and demonstrates the synergy of spectroscopic and isotopic approaches.

Culture-independent microbiology results show that microbial communities of the EPR change when chimney structures become hydrothermally extinct (Sylvan et al., 2012). Once extinct, the EPR sulfide deposits host bacterial communities similar in composition and structure to midocean ridge sulfides from far distant sites, such as the Indian Ocean (Toner et al., 2013). The presence of bacterial groups known for Fe and S cycling in EPR sulfide samples (e.g., $\beta$ Proteobacteria Gallionella sp. and $\varepsilon$-Proteobacteria Sulfurimonas sp.) indicates that microorganisms should be able to mediate the alteration of sulfide mineral substrates. As a result of $S$ and/or $\mathrm{Fe}$ oxidation processes, $\mathrm{Fe}$ (III) reaction products are expected, and $\mathrm{Fe}$ (III)-bearing phases are abundant in the EPR sulfide deposits examined in this study. Overall, these findings provide evidence to support the idea that inactive sulfide deposits are more than passive surfaces for microbial attachment. However, only the genetic potential, not the metabolic capabilities, of microbial community members are measured by the sequencing approaches used to-date for this sample set.

While our analysis of Fe mineralogy and isotope values do not support or refute a unique biological role in $\mathrm{Fe}$ (III) oxyhydroxide precipitation during sulfide alteration, our findings do reveal complex reaction pathways of $\mathrm{Fe}$ - precipitation/dissolution and oxidation/reduction-in seafloor sulfide deposits. The variety of Fe transformation pathways we observe is consistent with the development of micro-environments within the sulfide deposits. By defining four pathways of Fe transformation, we can propose several micro-environments. We observe zones of mixing between vent fluids and seawater with both reducing (Pathways 1 and 2) and oxidizing conditions (Pathways 2 and 4). These micro-environments are consistent with the diverse genetic potential, and correspondingly wide range of potential metabolisms, observed in organisms cultured from sulfide deposits. The reducing-to-oxidizing range of mixing zones, in particular, could support micro-environments favorable to $\mathrm{Fe}$ and $\mathrm{S}$ oxidation and reduction within a single chimney deposit.

In contrast to the dynamic multi-step pathways revealed by $\mathrm{Fe}$ isotopes, the Fe XAS observations for these samples are consistent with stabilization of poorly ordered Fe(III) oxyhydroxide phases when Si and As are present. At first glance, it is surprising that multi-stage Fe oxidation and precipitation processes would preserve poorly ordered, and presumably, metastable $\mathrm{Fe}(\mathrm{III})$ oxyhydroxide phases. However, laboratory experiments have demonstrated that $\mathrm{Fe}$ atom replacement within Fe(III) oxyhydroxides, such as goethite, can produce the same mineral structure and particle morphology in the presence of Fe(II)aq (Handler et al., 2009). While there are many time-dependent factors that our measurements cannot assesstemperature, flow-rate, time-resolved vent fluid chemistry-the dynamic history supported by the Fe isotopes and static history supported by the mineralogy leads us to conclude that inorganic ligands (As, Si), and possibly biological material (Toner et al., 2009b, 2012), stabilize poorly ordered Fe(III) oxyhydroxide phases in these deposits. In addition, ligands appear to be retained by the deposit throughout a complex set of $\mathrm{Fe}$ transformation events and dynamic re-working of the Fe-bearing alteration products. It is possible that this mineral-stabilization outcome is driven by a decrease in permeability of the sulfide deposits as a function of time. Low-flow conditions could lead to the retention of ligands in pore spaces and preservation metastable phases despite continued alteration of the Febearing minerals. The physical and chemical environments created by seafloor sulfide deposits do not appear to provide unique biosignatures. However, they do appear to be promising recorders of micro-environmental conditions present during hydrothermal activity.

\section{AUTHOR CONTRIBUTIONS}

Authors CS, OR, WB, and KE collected the samples, OR analyzed samples for Fe and $\mathrm{S}$ isotopes, BT and CS analyzed samples for $\mathrm{Fe}$ mineralogy, and BT, OR, CS, and WB prepared the manuscript.

\section{ACKNOWLEDGMENTS}

For financial support we thank: NASA for a small grant for laser ablation MC-ICP-MS measurements (BMT); the National Research Council Associate and NASA Postdoctoral Programs (BMT); RIDGE 2000 (OCE-0241791; KJE and WB); and CFANS University of Minnesota (BMT); LabexMer (ANR-10-LABX-19-01; OJR). For research support we thank: M. K. Tivey, G. A. Gaetani, and M. Sulanowska (Woods Hole Oceanographic Institution) for making laboratory space, 
wafering saw, petrographic microscope, and polishing equipment available; M. A. Marcus for support at ALS BL10.3.2; N. Tamura for support at ALS BL 7.3.3; C. M. Hansel and S. Fendorf for providing iron EXAFS reference spectra; E. Ponzevera and Y. Germain for maintaining the mass spectrometry facility and clean lab at Ifremer; and L. J. Briscoe for scanning electron microscopy imaging. The Advanced Light Source (ALS) is supported by the Office of Science, Basic Energy Sciences, Division of Materials Science of the U.S. Department of Energy (DE-AC02-05CH11231). Part of this work was carried out at the Institute of Technology, Characterization Facility, University of Minnesota (an NSF-funded Materials Research Facilities Network).

\section{SUPPLEMENTARY MATERIAL}

The Supplementary Material for this article can be found online at: http://journal.frontiersin.org/article/10.3389/fmicb. 2016.00648

Figure S1 | Seafloor photographs of sampling sites. $(A, B)$ Location of $K$ Vent samples EPR-4053-M2, EPR-4053-M1-A1, and EPR-4053-M1-A2. (C,D) Massive sulfide deposits in the Bio9 Vent area EPR-4057-M2 and EPR-4059-M3, respectively. (E) Off axis, extinct chimney sources of sample EPR-4059-M4. Images previously published in various forms in Rouxel et al., 2008a; Sylvan et al., 2012; Toner et al., 2013.

Figure S2 | Shipboard photographs of samples.

Figure $\mathrm{S} 3$ | Shipboard photographs of $\mathrm{K}$ Vent inactive spire showing the locations of EPR-4053-M1-A1 and EPR-4053-M1-A2. Portions of this figure are published in Rouxel et al., 2008b

Figure S4 | Photographs of polished thick sections showing the regions of the sample investigated.

Figure S5 | Example laser ablation run.

Figure S6 | Iron isotope values as a function of S:Fe and Si:Fe.

Figure S7 | (A) Synchrotron radiation microprobe X-ray diffraction data from spot 2 of EPR-4057-M2. (B) Data with goethite reference lines.

\section{REFERENCES}

Alt, J. C. (1988). Hydrothermal oxide and nontronite deposits on seamounts in the eastern Pacific. Mar. Geol. 81, 227-239. doi: 10.1016/0025-3227(88)90029-1

Amend, J. P., McCollom, T. M., Hentscher, M., and Bach, W. (2011). Catabolic and anabolic energy for chemolithoautotrophs in deep-sea hydrothermal systems hosted in different rock types. Geochim. Cosmochim. Acta 75, 5736-5748. doi: 10.1016/j.gca.2011.07.041

Anbar, A. D., Jarzecki, A. A., and Spiro, T. G. (2005). Theoretical investigation of iron isotope fractionation between $\mathrm{Fe}(\mathrm{H} 2 \mathrm{O}) 63+$ and $\mathrm{Fe}(\mathrm{H} 2 \mathrm{O}) 62+$ : implications for iron stable isotope geochemistry. Geochim. Cosmochim. Acta 69, 825-837. doi: 10.1016/j.gca.2004.06.012

Beard, B. L., Handler, R. M., Scherer, M. M., Wu, L. L., Czaja, A. D., Heimann, A., et al. (2010). Iron isotope fractionation between aqueous ferrous iron and goethite. Earth Planet. Sci. Lett. 295, 241-250. doi: 10.1016/j.epsl.2010.04.006

Beard, B. L., Johnson, C. M., Skulan, J. L., Nealson, K. H., Cox, L., and Sun, H. (2003b). Application of Fe isotopes to tracing the geochemical and biological cycling of Fe. Chem. Geol. 195, 87-117. doi: 10.1016/S0009-2541(02)00390-X

Beard, B. L., Johnson, C. M., Von Damm, K. L., and Poulson, R. L. (2003a). Iron isotope constraints on $\mathrm{Fe}$ cycling and mass balance in oxygenated Earth oceans. Geology 31, 629-632. doi: 10.1130/0091-7613(2003)031<0629:IICOFC > 2.0.CO;2
Figure S8 | Petrographic microscope images of sample EPR-4057-M2. (A) Iron oxyhydroxide accumulations at the seawater exposed surface of the massive sulfide deposit. (B) Oxidation of pyrrhotite crystals. (C,D) Sulfide minerals.

Figure S9 | Summary of Fe EXAFS data (dots) and best linear combination fit (solid lines). Goodness of fit parameters (Table S4) and key for reference materials (Table S2) are provided in the main text.

Table S1 | Summary of sample locations and naming conventions.

Table S2 | Summary of Fe-bearing reference materials used for linear combination fitting (LCF) of $\mathbf{X}$-ray absorption spectra. The $\chi^{2}, R$-value, and SPOIL parameters are derived from principal component (PCA) and target transformation analysis (TTA).

Table S3 | Linear combination fit results for Fe X-ray absorption near edge structure (XANES) spectra. Fit components are listed along with the mol\% attributed to each component. The components (reference spectra) contributing to the best fit are described in Table S2. The normalized sum square (NSS) parameter is an indicator of the goodness of the fit. An * symbol indicates that extended X-ray absorption fine structure (EXAFS) spectra were also collected (Table S4). The "Over Absorption Correction" is defined in the Section Synchrotron Microprobe X-ray Absorption Spectroscopy (XAS) Analysis.

Table S4 | Linear combination fit results for Fe extended X-ray absorption fine structure (EXAFS) spectra. Fit components are listed along with the mol\% attributed to each component. The components (reference spectra) contributing to the best fit are described in Table S2. The chi square parameter $\left(\chi^{2}\right)$ is an indicator of the goodness of the fit.

Table S5 | Iron and S isotope analyses for sample EPR-4053-M3-reg1 (K Vent). Laser ablation (LA) and micro-drill (MD) sampling are organized according to the dominant mineralogy at that location (pyrite and oxyhydroxide). Specific locations of sampling are displayed in Figure 2. One standard deviation $(\sigma)$ is reported.

Table S6 | Iron isotope analyses for sample EPR-4057-M2 (Bio9 Area). Laser ablation (LA) and micro-drill (MD) sampling are organized according to the dominant mineralogy at that location (pyrite and oxyhydroxide). Specific locations of sampling are displayed in Figure 4A. One standard deviation $(\sigma)$ is reported.

Table S7 | Iron isotope analyses for sample EPR-4059-M4 (off-axis chimney). Laser ablation (LA) and micro-drill (MD) sampling are organized according to the dominant mineralogy at that location (pyrite and oxyhydroxide). Specific locations of sampling are displayed in Figures 4B, 7A,B. One standard deviation $(\sigma)$ is reported.

Bennett, S. A., Achterberg, E. P., Connelly, D. P., Statham, P. J., Fones, G. R., and German, C. R. (2008). The distribution and stabilisation of dissolved Fe in deep-sea hydrothermal plumes. Earth Planet. Sci. Lett. 270, 157-167. doi: 10.1016/j.epsl.2008.01.048

Boyd, T. D., and Scott, S. D. (2001). Microbial and hydrothermal aspects of ferric oxyhydroxides and ferrosic hydroxides: the example of Franklin Seamount, Western Woodlark Basin, Papua New Guinea. Geochem. Trans. 2, 45. doi: 10.1039/b105277m

Breier, J. A., Toner, B. M., Fakra, S. C., Marcus, M. A., White, S. N., Thurnherr, A. M., et al. (2012). Sulfur, sulfides, oxides and organic matter aggregated in submarine hydrothermal plumes at $9^{\circ} 50^{\prime} \mathrm{N}$ East Pacific Rise. Geochim. Cosmochim. Acta 88, 216-236. doi: 10.1016/j.gca.2012.04.003

Bullen, T. D., White A. F., Childs, C. W., Vivit, D. V., and Schultz, M. S. (2001). Demonstration of a significant iron isotope fractionation in nature. Geology 29, 699-702. doi: 10.1130/0091-7613(2001)029<0699:DOSAII > 2.0.CO

Byrne, N., Strous, M., Crépeau, V., Kartal, B., Birrien, J.-L., Schmid, M., et al. (2009). Presence and activity of anaerobic ammonium-oxidizing bacteria at deep-sea hydrothermal vents. ISME J. 3, 117-123. doi: 10.1038/ismej.2008.72

Callac, N., Rouxel, O., Lesongeur, F., Liorzou, C., Bollinger, C., Pignet, P., et al. (2015). Biogeochemical insights into microbe-mineral-fluid interactions in hydrothermal chimneys using enrichment culture. Extremophiles 19, 597-617. doi: $10.1007 / \mathrm{s} 00792-015-0742-5$ 
Combes, J. M., Manceau, A., Calais, G., and Bottero, J. Y. (1989). Formation of ferric oxides from aqueous solutions: a polyhedral approach by $\mathrm{X}$-ray absorption spectroscopy: I. Hydrolysis and formation of ferric gels. Geochim. Cosmochim. Acta 53, 583-594. doi: 10.1016/0016-7037(89)90001-x

Craddock, P. R., Rouxel, O. J., Ball, L. A., and Bach, W. (2008). Sulfur isotope measurement of sulfate and sulfide by high-resolution MC-ICP-MS. Chem. Geol. 253, 102-113. doi: 10.1016/j.chemgeo.2008.04.017

Croal, L. R., Johnson, C. M., Beard, B. L., and Newman, D. K. (2004). Iron isotope fractionation by $\mathrm{Fe}(\mathrm{II})$-oxidizing photoautotrophic bacteria. Geochim. Cosmochim. Acta 68, 1227-1242. doi: 10.1016/j.gca.2003.09.011

Dauphas, N., and Rouxel, O. (2006). Mass spectrometry and natural variations of iron isotopes. Mass Spectrom. Rev. 25, 515-550. doi: 10.1002/mas.20078

Druschel, G. K., Emerson, D., Sutka, R., Suchecki, P., and Luther, I. I. I. G. W. (2008). Low-oxygen and chemical kinetic constraints on the geochemical niche of neutrophilic iron(II) oxidizing microorganisms. Geochim. Cosmochim. Acta 72, 3358-3370. doi: 10.1016/j.gca.2008.04.035

Edmond, J. M., Measures, C., McDuff, R. E., Chan, L. H., Collier, R., Grant, B., et al. (1979). Ridge crest hydrothermal activity and the balances of the major and minor elements in the ocean: the Galapagos data. Earth Planet. Sci. Lett. 46, 1-18. doi: 10.1016/0012-821X(79)90061-X

Edwards, K. J., Bach, W., and Rogers, D. R. (2003a). Geomicrobiology of the ocean crust: a role for chemolithoautotrophic Fe-bacteria. Biol. Bull. 204, 180-185. doi: $10.2307 / 1543555$

Edwards, K. J., Glazer, B. T., Rouxel, O. J., Bach, W., Emerson, D., Davis, R. E., et al. (2011). Ultra-diffuse hydrothermal venting supports Fe-oxidizing bacteria and massive umber deposition at 5000 off Hawaii. ISME J. 5, 1-11. doi: 10.1038/ismej.2011.48

Edwards, K. J., McCollom, T. M., Konishi, H., and Buseck, P. R. (2003b). Seafloor bioalteration of sulfide minerals: results from in situ incubation studies. Geochim. Cosmochim. Acta 67, 2843-2856. doi: 10.1016/S0016-7037(03)0 0089-9

Elderfield, H., and Schultz, A. (1996). Mid-ocean ridge hydrothermal fluxes and the chemical composition of the ocean. Annu. Rev. Earth Planet. Sci. 24, 191-224. doi: 10.1146/annurev.earth.24.1.191

Emerson, D. (2016). The irony of iron - biogenic iron oxides as an iron source to the Ocean. Front. Microbiol. 6:1502. doi: 10.3389/fmicb.2015.01502

Emerson, D., and Moyer, C. L. (2002). Neutrophilic Fe-oxidizing bacteria are abundant at the Loihi seamount hydrothermal vents and play a major role in Fe oxide deposition. Appl. Environ. Microbiol. 68, 3085-3093. doi: 10.1128/AEM.68.6.3085-3093.2002

Feely, R. A., Gendron, J. F., and Baker, E. T. (1994). Hydrothermal plumes along the East Pacific Rise, $840^{\prime}$ to $1150^{\prime} \mathrm{N}$ : particle distribution and composition. Earth Planet. Sci. Lett. 128, 19-36. doi: 10.1016/0012-821X(94)90023-X

Feely, R. A., Massoth, G. J., Baker, B. J., Lebon, G. T., and Geiselman, T. I. (1992). Tracking the dispersal of hydrothermal plumes from the Juan de Fuca Ridge using suspended matter compositions. J. Geophys. Res. 97, 3457-3468. doi: 10.1029/91JB03062

Field, M. P., and Sherrell, R. M. (2000). Dissolved and particulate Fe in a hydrothermal plume at 9 o $45^{\prime} \mathrm{N}$, East Pacific Rise: slow Fe(II) oxidation kinetics in Pacific plumes. Geochim. Cosmochim. Acta 64, 619-628. doi: 10.1016/s0016-7037(99)00333-6

Fitzsimmons, J. N., Boyle, E. A., and Jenkins, W. J. (2014). Distal transport of dissolved hydrothermal iron in the deep South Pacific Ocean. Proc. Natl. Acad. Sci. U.S.A. 111, 16654-16661. doi: 10.1073/pnas.1418778111

Fouquet, Y., Cambon, P., Etoubleau, J., Charlou, J. L., Ondreas, H., Barriga, F., et al. (2010). "Geodiversity of hydrothermal processes along the Mid-Atlantic Ridge-ultramafic-hosted mineralization: a new type of Oceanic Cu-Zn-CoAu VMS deposit," in Diversity of Hydrothermal Systems on Slow-spreading Ocean Ridges, ed P. Rona (Washington DC: American Geophysical Union), 321-367.

Graham, S., Pearson, N. J., Jackson, S., Griffin, W., and O’Reilly, S. Y. (2004). Tracing $\mathrm{Cu}$ and $\mathrm{Fe}$ from source to porphyry: in situ determination of $\mathrm{Cu}$ and $\mathrm{Fe}$ isotope ratios in sulfides from the Grasberg $\mathrm{Cu}-\mathrm{Au}$ deposit. Chem. Geol. 207, 147-169. doi: 10.1016/j.chemgeo.2004.02.009

Handler, R. M., Beard, B. L., Johnson, C. M., and Scherer, M. M. (2009). Atom exchange between Aqueous Fe (II) and Goethite: an Fe isotope tracer Study. Environ. Sci. Technol. 43, 1102-1107. doi: 10.1021/es802402m
Hannington, M. D., Jonasson, I. R., Herzig, P. M., and Peterson, S. (1995). "Physical and chemical processes of seafloor mineralization at Mid-Ocean ridges," in Seafloor Hydrothermal Systems: Physical, Chemical, Biological, and Geological Interactions, eds S. E. Humphris, R. A. Zierenberg, L. S. Mullineaux, and R. E. Thomson (Washington, DC: American Geophysical Union), $115-157$.

Hansel, C. M., Benner, S. G., Neiss, J., Dohnalkova, A., Kukkadapu, R. K., and Fendorf, S. (2003). Secondary mineralization pathways induced by dissimilatory iron reduction of ferrihydrite under advective flow. Geochim. Cosmochim. Acta 67, 2977-2992. doi: 10.1016/S0016-7037(03) 00276-X

Hawkes, J. A., Connelly, D. P., Gledhill, M., and Achterberg, E. P. (2013). The stabilization and transportation of dissolved iron from high temperature hydrothermal vent systems. Earth Planet. Sci. Lett. 375, 280-290. doi: 10.1016/j.epsl.2013.05.047

Holden, J., and Adams, M. W. W. (2003). Microbe-metal interactions in marine hydrothermal environments. Curr. Opin. Chem. Biol. 7, 160-165. doi: 10.1016/S1367-5931(03)00026-7

Horn, I., von Blanckenburg, F., Schoenberg, R., Steinhoefel, G., and Markl, G. (2006). In situ iron isotope ratio determination using UV-femtosecond laser ablation with application to hydrothermal ore formation processes. Geochim. Cosmochim. Acta 70, 3677-3688. doi: 10.1016/j.gca.2006. 05.002

Houghton, J. L., and Seyfried, W. E. Jr. (2010). An experimental and theoretical approach to determining linkages between geochemical variability and microbial diversity in seafloor hydrothermal chimneys. Geobiology 8, 457-470. doi: 10.1111/j.1472-4669.2010.00255.x

Houghton, R. A. (2007). Balancing the global carbon budget. Annu. Rev. Earth Planet. Sci. 35, 313-347. doi: 10.1146/annurev.earth.35.031306.140057

Icopini, G. A., Anbar, A. D., Ruebush, S. S., Tien, M., and Brantley, S. L. (2004). Iron isotope fractionation during microbial reduction of iron: the importance of adsorption. Geology 32, 205-208. doi: 10.1130/G20184.1

Johnson, C. M., and Beard, B. L. (2005). Biogeochemical cycling of iron isotopes. Science 309, 1025-1027. doi: 10.1126/science.1112552

Johnson, C. M., Beard, B. L., Beukes, N. J., Klein, C., and O’Leary, J. M. (2003). Ancient geochemical cycling in the Earth as inferred from Fe isotope studies of banded iron formations from the Transvaal Craton. Contrib. Mineral. Petrol. 144, 523-547. doi: 10.1007/s00410-002-0418-x

Johnson, C. M., Beard, B. L., and Roden, E. E. (2008). The iron isotope fingerprints of redox and biogeochemical cycling in the modern and ancient Earth. Annu. Rev. Earth Planet. Sci. 36, 457-493. doi: 10.1146/annurev.earth.36.031207.124139

Karl, D. M. (1995). "Ecology of free-living, hydrothermal vent microbial communities," in The Microbiology of Deep-Sea Hydrothermal Vents, ed D. M. Karl (Boca Raton, FL: CRC Press), 35-124.

Kraft, S., Stümpel, J., Becker, P., and Kuetgens, U. (1996). High resolution $\mathrm{x}$-ray absorption spectroscopy with absolute energy Calibration for the determination of absorption edge energies. Rev. Sci. Instrum. 67, 681-687. doi: 10.1063/1.1146657

Lever, M. A., Rouxel, O., Alt, J. C., Shimizu, N., Ono, S. H., Coggon, R. M., et al. (2013). Evidence for microbial carbon and sulfur cycling in deeply buried ridge flank basalt. Science 339, 1305-1308. doi: 10.1126/science.1229240

Li, M., Toner, B. M., Baker, B. J., Breier, J. A, Sheik, C. S., and Dick, G. J. (2014). Microbial iron uptake as a mechanism for dispersing iron from deep-sea hydrothermal vents. Nat. Commun. 5, 3192. doi: 10.1038/ncomms4192

Little, C. T. S., Magalashvili, A. G., and Banks, D. A. (2007). Neotethyan Late Cretaceous volcanic arc hydrothermal vent fauna. Geology 35, 835-838. doi: 10.1130/G23957A.1

Manceau, A., Marcus, M. A., and Tamura, N. (2002). Quantitative speciation of heavy metals in soils and sediments by synchrotron X-ray techniques. Rev. Mineral. Geochem. 49, 341-428. doi: 10.2138/gsrmg.49.1.341

Marcus, M. A., Edwards, K. J., Gueguen, B., Fakra, S. C., Horn, G., Jelinski, N., et al. (2015). Iron mineral structure, reactivity, and isotopic composition in a South Pacific Gyre ferromanganese nodule over $4 \mathrm{Ma}$. Geochim. Cosmochim. Acta 171, 61-79. doi: 10.1016/j.gca.2015.08.021

Marcus, M. A., MacDowell, A., Celestre, R., Manceau, A., Miller, T., Padmore, H. A., et al. (2004). Beamline 10.3.2 at ALS: a hard X-ray microprobe for 
environmental and material sciences. J. Synchrotron Rad. 11, 239-247. doi: $10.1107 /$ S0909049504005837

Marcus, M. A., Westphal, A. J., and Fakra, S. (2008). Classification of $\mathrm{Fe}-$ bearing species from K-edge XANES data using two-parameter correlation plots. J. Synchrotron Rad. 15, 463-468. doi: 10.1107/S09090495080 18293

Mason, P. R. D., Kosler, J., de Hoog, J. C. M., Sylvester, P. J., Meffan-Main, S., Košler, J., et al. (2006). In situ determination of sulfur isotopes in sulfurrich materials by laser ablation multiple-collector inductively coupled plasma mass spectrometry (LA-MC-ICP-MS). J. Anal. At. Spectrom. 21, 177-186. doi: 10.1039/B510883G

Michel, F. M., Ehm, L., Antao, S. M., Lee, P. L., Chupas, P. J., Liu, G., et al. (2007). The structure of ferrihydrite, a nanocrystalline material. Science 316, 1726-1729. doi: 10.1126/science.1142525

Mills, R. A., and Elderfield, H. (1995). Rare earth element geochemistry of hydrothermal deposits from the active TAG Mound, $26^{\circ} \mathrm{N}$ Mid-Atlantic Ridge. Geochim. Cosmochim. Acta 59, 3511-3524. doi: 10.1016/0016-7037(95)00224$\mathrm{N}$

Moeller, K., Schoenberg, R., Grenne, T., Thorseth, I. H., Drost, K., and Pedersen, R. B. (2014). Comparison of iron isotope variations in modern and Ordovician siliceous Fe oxyhydroxide deposits. Geochim. Cosmochim. Acta 126, 422-440. doi: 10.1016/j.gca.2013.11.018

Nakagawa, S., Takai, K., Inagaki, F., Hirayama, H., Nunoura, T., Horikoshi, K., et al. (2005). Distribution, phylogenetic diversity and physiological characteristics of epsilon-Proteobacteria in a deep-sea hydrothermal field. Env. Microbiol. 7, 1619-1632. doi: 10.1111/j.1462-2920.2005.00856.x

Nishizawa, M., Yamamoto, H., Ueno, Y., Tsuruoka, S., Shibuya, T., Sawaki, Y., et al. (2010). Grain-scale iron isotopic distribution of pyrite from Precambrian shallow marine carbonate revealed by a femtosecond laser ablation multicollector ICP-MS technique: possible proxy for the redox state of ancient seawater. Geochim. Cosmochim. Acta 74, 2760-2778. doi: 10.1016/j.gca.2010.02.014

O’Day, P. A., Rivera, N. Jr., Root, R., and Carroll, S. A. (2004). X-ray absorption spectroscopic study of Fe reference compounds for the analysis of natural sediments. Am. Miner. 89, 572-585. doi: 10.2138/am-2004-0412

Orcutt, B. N., Bach, W., Becker, K., Fisher, A. T., Hentscher, M., Toner, B. M., et al. (2011). Colonization of subsurface microbial observatories deployed in young ocean crust. ISME J. 5, 692-703. doi: 10.1038/ismej.2010.157

Pagé, A., Tivey, M. K., Stakes, D. S., and Reysenbach, A.-L. (2008). Temporal and spatial archaeal colonization of hydrothermal vent deposits. Environ. Microbiol. 10, 874-884. doi: 10.1111/j.1462-2920.2007.01505.x

Paris, G., Sessions, A. L., Subhas, A. V., and Adkins, J. F. (2013). MC-ICP-MS measurement of delta S-34 and delta S-33 in small amounts of dissolved sulfate. Chem. Geol. 345, 50-61. doi: 10.1016/j.chemgeo.2013.02.022

Peters, M., Strauss, H., Farquhar, J., Ockert, C., Eickmann, B., and Jost, C. L. (2010). Sulfur cycling at the Mid-Atlantic Ridge: a multiple sulfur isotope approach. Chem. Geol. 269, 180-196. doi: 10.1016/j.chemgeo.2009.09.016

Planavsky, N., Rouxel, O. J., Bekker, A., Hofmann, A., Little, C. T. S., and Lyons, T. W. (2012). Iron isotope composition of some Archean and Proterozoic iron formations. Geochim. Cosmochim. Acta 80, 158-169. doi: 10.1016/j.gca.2011.12.001

Poitrasson, F., and Freydier, R. (2005). Heavy iron isotope composition of granites determined by high resolution MC-ICP-MS. Chem. Geol. 222, 132-147. doi: 10.1016/j.chemgeo.2005.07.005

Prietzel, J., Thieme, J., Eusterhues, K., and Eichert, D. (2007). Iron speciation in soils and soil aggregates by synchrotron-based X-ray microspectroscopy (XANES, micro-XANES). Eur. J. Soil Sci. 58, 1027-1041. doi: 10.1111/j.13652389.2006.00882.x

Resing, J. A., Sedwick, P. N., German, C. R., Jenkins, W. J., Moffett, J. W., Sohst, B., et al. (2015). Basin-scale transport of hydrothermal dissolved metals across the South Pacific Ocean. Nature 523, 200-206. doi: 10.1038/nature 14577

Reysenbach, A. L., and Cady, S. L. (2001). Microbiology of ancient and modern hydrothermal systems. Trends Microbiol. 9, 79-86. doi: 10.1016/S0966$842 X(00) 01921-1$

Rouxel, O., Dobbek, N., Ludden, J., and Fouquet, Y. (2003). Iron isotope fractionation during oceanic crust alteration. Chem. Geol. 202, 155-182. doi: 10.1016/j.chemgeo.2003.08.011
Rouxel, O., Fouquet, Y., and Ludden, J. N. (2004). Subsurface processes at the lucky strike hydrothermal field, Mid-Atlantic ridge: evidence from sulfur, selenium, and iron isotopes. Geochim. Cosmochim. Acta 68, 2295-2311. doi: 10.1016/j.gca.2003.11.029

Rouxel, O., Shanks, W. C. III, Bach, W., and Edwards, K. J. (2008a). Integrated Feand S-isotope study of seafloor hydrothermal vents at East Pacific Rise $9-10^{\circ} \mathrm{N}$. Chem. Geol. 252, 214-227. doi: 10.1016/j.chemgeo.2008.03.009

Rouxel, O., Sholkovitz, E., Charette, M., and Edwards, K. J. (2008b). Iron isotope fractionation in subterranean estuaries. Geochim. Cosmochim. Acta 72, 3413-3430. doi: 10.1016/j.gca.2008.05.001

Rouxel, O. J., Bekker, A., and Edwards, K. J. (2005). Iron isotope constraints on the Archean and Paleoproterozoic ocean redox state. Science 307, 1088-1091. doi: 10.1126/science.1105692

Saito, M. A., Noble, A. E., Tagliabue, A., Goepfert, T. J., Lamborg, C. H., and Jenkins, W. J. (2013). Slow-spreading submarine ridges in the South Atlantic as a significant oceanic iron source. Nat. Geosci. 6, 775-779. doi: 10.1038/ngeo1893

Santelli, C. M., Orcutt, B. N., Benning, E., Bach, W., Moyer, C. L., Sogin, M. L. et al. (2008). Abundance and diversity of microbial life in ocean crust. Nature 453, 653-657. doi: 10.1038/nature06899

Schrenk, M. O., Kelley, D. S., Delaney, J. R., and Baross, J. A. (2003). Incidence and diversity of microorganisms within the walls of an active deep-sea sulfide chimney. Appl. Environ. Microbiol. 69, 3580-3592. doi: 10.1128/AEM.69.6.3580-3592.2003

Severmann, S., Johnson, C. M., Beard, B. L., German, C. R., Edmonds, H. N., Chiba, H., et al. (2004). The effect of plume processes on the Fe isotope composition of hydrothermally derived Fe in the deep ocean as inferred from the Rainbow vent site, Mid-Atlantic Ridge, 36 degrees 14' N. Earth Planet. Sci. Lett. 225, 63-76. doi: 10.1016/j.epsl.2004.06.001

Severmann, S., Johnson, C. M., Beard, B. L., and McManus, J. (2006). The effect of early diagenesis on the $\mathrm{Fe}$ isotope compositions of porewaters and authigenic minerals in continental margin sediments. Geochim. Cosmochim. Acta 70, 2006-2022. doi: 10.1016/j.gca.2006.01.007

Sharma, M., Polizzotto, M., and Anbar, A. D. (2001). Iron isotopes in hot springs along the Juan de Fuca Ridge. Earth Planet. Sci. Lett. 194, 39-51. doi: 10.1016/S0012-821X(01)00538-6

Slobodkin, A., Campbell, B., Cary, S. C., Bonch-Osmolovskaya, E., and Jeanthon, C. (2001). Evidence for the presence of thermophilic $\mathrm{Fe}(\mathrm{III})$-reducing microorganisms in deep-sea hydrothermal vents at $13^{\circ} \mathrm{N}$ (East Pacific Rise). FEMs Microbiol. Ecol. 36, 235-243. doi: 10.1016/s0168-6496(01)00138-6

Stein, C., and Stein, S. (1994). Constraints on hydrothermal Heat-Flux through the oceanic lithosphere from global heat-flow. J. Geophys. Res. 99, 3081-3095. doi: 10.1029/93JB02222

Swanner, E. D., Wu, W., Schoenberg, R., Byrne, J., Michel, F. M., Pan, Y., et al. (2015). Fractionation of $\mathrm{Fe}$ isotopes during $\mathrm{Fe}(\mathrm{II})$ oxidation by a marine photoferrotroph is controlled by the formation of organic Fe-complexes and colloidal Fe fractions. Geochim. Cosmochim. Acta 165, 44-61. doi: 10.1016/j.gca.2015.05.024

Sylvan, J. B., Toner, B. M., and Edwards, K. J. (2012). Life and death of deep-sea vents: bacterial diversity and ecosystem succession on inactive hydrothermal sulfides. MBio 3, 1-12. doi: 10.1128/mBio.00279-11

Takai, K., Nunoura, T., Ishibashi, J. I., Lupton, J., Suzuki, R., Hamasaki, H., et al. (2008). Variability in the microbial communities and hydrothermal fluid chemistry at the newly discovered Mariner hydrothermal field, southern Lau Basin. J. Geophys. Res. 113:G02031. doi: 10.1029/2007JG000636

Tamura, N., Celestre, R. S., MacDowell, A. A., Padmore, H. A., Spolenak, R., Valek, B. C., et al. (2002). Submicron x-ray diffraction and its application to problems in materials and environmental science. Rev. Sci. Instrum. 73, 1369-1372. doi: $10.1063 / 1.1436539$

Tamura, N., MacDowell, A. A., Spolenak, R., Valek, B. C., Bravman, J. C., Brown, W. L., et al. (2003). Scanning X-ray Microdiffraction with submicron white beam for strain/stress and orientation mapping in thin films. J. Synchrotron Radiat. 10, 137-143. doi: 10.1107/S0909049502021362

Templeton, A. S., Knowles, E. J., Eldridge, D. L., Arey, B. W., Dohnalkova, A. C., Webb, S. M., et al. (2009). A seafloor microbial biome hosted within incipient ferromanganese crusts. Nat. Geosci. 2, 872-876. doi: 10.1038/ngeo696

Tivey, M. K. (1995). The influence of hydrothermal fluid composition and advection rates on black smoker chimney mineralogy: insights from modeling 
transport and reaction. Geochim. Cosmochim. Acta 59, 1933-1949. doi: 10.1016/0016-7037(95)00118-2

Tivey, M. K. (2007). Generation of Seafloor Hydrothermal Vent Fluids and Associated Mineral Deposits. Oceanography 20, 50-65. doi: 10.5670/oceanog. 2007.80

Toner, B., Manceau, A., Webb, S. M., and Sposito, G. (2006). Zinc sorption to biogenic hexagonal-birnessite particles within a hydrated bacterial biofilm. Geochim. Cosmochim. Acta 70, 27-43. doi: 10.1016/j.gca.2005. 08.029

Toner, B. M., Berquo, T. S., Michel, F. M., Sorensen, J. V., Templeton, A. S., and Edwards, K. J. (2012). Mineralogy of iron microbial mats from Loihi Seamount. Front. Microbiol. Chem. 3:118. doi: 10.3389/fmicb.2012.00118

Toner, B. M., Fakra, S. C., Manganini, S. J., Santelli, C. M., Marcus, M. A., Moffett, J. W., et al. (2009a). Preservation of iron(II) by carbon-rich matrices in a hydrothermal plume. Nat. Geosci. 2, 197-201. doi: 10.1038/ngeo433

Toner, B. M., Lesniewski, R. A., Marlow, J. J., Briscoe, L. J., Santelli, C. M., Bach, W., et al. (2013). Mineralogy drives bacterial biogeography of hydrothermally inactive seafloor sulfide deposits. Geomicrobiol. J. 30, 313-326. doi: 10.1080/01490451.2012.688925

Toner, B. M., Santelli, C. M., Marcus, M. A., Wirth, R., Chan, C. S., McCollom, T. M., et al. (2009b). Biogenic iron oxyhydroxide formation at Mid-Ocean Ridge hydrothermal vents: juan de Fuca Ridge. Geochim. Cosmochim. Acta 73, 388-403. doi: 10.1016/j.gca.2008.09.035

Webb, S. M. (2005). SIXPACK: a graphical user interface for XAS analysis using IFEFFIT. Phys. Scr. T115, 1011-1014. doi: 10.1238/Physica.Topical.115a01011

Welch, S. A., Beard, B. L., Johnson, C. M., and Braterman, P. S. (2003). Kinetic and equilibrium $\mathrm{Fe}$ isotope fractionation between aqueous $\mathrm{Fe}(\mathrm{II})$ and $\mathrm{Fe}$ (III). Geochim. Cosmochim. Acta 67, 4231-4250. doi: 10.1016/S0016-7037(03)0 0266-7

Wheat, C. G., Jannasch, H. W., Plant, J. N., Moyer, C. L., Sansone, F. J., and McMurtry, G. M. (2000). Continuous sampling of hydrothermal fluids from
Loihi Seamount after the 1996 event. J. Geophys. Res. Earth 105, 19353-19367. doi: 10.1029/2000JB900088

Wheat, C. G., Mottl, M. J., Fisher, A. T., Kadko, D., Davis, E. E., and Baker, E. (2004). Heat flow through a basaltic outcrop on a sedimented young ridge flank. Geochem. Geophys. Geosyst. 5:Q12006. doi: 10.1029/2004GC000700

Wu, L. L., Druschel, G., Findlay, A., Beard, B. L., and Johnson, C. M. (2012). Experimental determination of iron isotope fractionations among Fe-aq(2+)-FeSaq-Mackinawite at low temperatures: implications for the rock record. Geochim. Cosmochim. Acta 89, 46-61. doi: 10.1016/j.gca.2012. 04.047

Xu, Q. D., and Scott, S. D. (2005). "Spherulitic pyrite in seafloor hydrothermal deposits: products of rapid crystallization from mixing fluids," in Mineral Deposit Research Meeting the Global Challenge, eds J. Mao and F. P. Bierlein (Berlin: Springer), 711-713.

Yamamoto, M., and Takai, K. (2011). Sulfur metabolisms in epsilon-and gammaproteobacteria in deep-sea hydrothermal fields. Front. Microbiol. 2:192. doi: 10.3389/fmicb.2011.00192

Yucel, M., Gartman, A., Chan, C. S., and George, W., Luther, I. I. I. (2011) Hydrothermal vents as a kinetically stable source of iron-sulphide-bearing nanoparticles to the ocean. Nat. Geosci. 4, 367-371. doi: 10.1038/ngeo1148

Conflict of Interest Statement: The authors declare that the research was conducted in the absence of any commercial or financial relationships that could be construed as a potential conflict of interest.

Copyright (C) 2016 Toner, Rouxel, Santelli, Bach and Edwards. This is an open-access article distributed under the terms of the Creative Commons Attribution License (CC $B Y)$. The use, distribution or reproduction in other forums is permitted, provided the original author(s) or licensor are credited and that the original publication in this journal is cited, in accordance with accepted academic practice. No use, distribution or reproduction is permitted which does not comply with these terms. 